\title{
Flora Polínica da Reserva do Parque Estadual das Fontes do Ipiranga (São Paulo, Brasil)
}

\author{
Família: 136-Solanaceae
}

\author{
Maria Amélia Vitorino da Cruz-Barros ${ }^{1,3}$, Elaine Lima Silva ${ }^{1}$, Eduardo Custódio Gasparino², \\ Ligia Novac Souza $^{1}$ e Anedi Costa de Oliveira ${ }^{1}$
}

Recebido: 03.08.2011; aceito: 29.12.2011

\begin{abstract}
Pollen flora of "Reserva do Parque Estadual das Fontes do Ipiranga" (São Paulo, Brazil). Family: 136-Solanaceae). Pollen grains of 12 genera and 41 species of Solanaceae occurring in the "Reserva do Parque Estadual das Fontes do Ipiranga" were examined: Acnistus arborescens (L.) Schlecht., Athenaea picta (Mart.) Sendtn., Brunfelsia latifolia Benth., Brunfelsia pauciflora (Cham. \& Schlecht.) Benth., Capsicum flexuosum (L.) Sendtn., Capsicum villosum (L.) Sendtn., Cestrum amictum (L.) Schlecht., Cestrum corymbosum (L.) Schlecht., Cestrum lanceolatum (L.) Miers, Cestrum schlechtendalii (L.) G. Don, Cestrum sendtnerianum (L.) Mart. ex Sendtn., Cyphomandra diploconos Sendtn., Cyphomandra velutina Sendtn., Dyssochroma viridiflora (Sims) Ducke, Nicotiana langsdorffii (Weinm.) Roem. \& Schult., Physalis peruviana L., Physalis viscosa L., Sessea brasiliensis Tol., Solandra grandiflora Sw, Solanum americanum Mill., Solanum atropurpureum Schrank., Solanum bullatum Vell., Solanum capsicoides Allion., Solanum cernuum Vell., Solanum concinnum Schott ex Sendtn., Solanum didynum Dun., Solanum diflorum Vell., Solanum excelsum St. Hil. ex Dun., Solanum granuloso-leprosum Dun., Solanum hoehnei Morton, Solanum inaequale Vell., Solanum inodornum Vell., Solanum lycocarpum St. Hil. ex Dun., Solanum mauritianum Scop., Solanum paniculatum L., Solanum rufescens Sendtn., Solanum sisymbriifolium Lam., Solanum swartzianum Roem. \& Schult., Solanum vaillantii Dun., Solanum variabile Mart., Solanum viarum Dun. Descriptions are presented for all species studied, including illustrations, additional observations and six key for identification.
\end{abstract}

Key words: pollen flora, pollen grains, Solanaceae

RESUMO - (Flora polínica da Reserva do Parque Estadual das Fontes do Ipiranga (São Paulo, Brasil). Família: 136Solanaceae) Foram estudados os grãos de pólen de 12 gêneros e 41 espécies de Solanaceae ocorrentes na "Reserva do Parque Estadual das Fontes do Ipiranga": Acnistus arborescens (L.) Schlecht., Athenaea picta (Mart.) Sendtn., Brunfelsia latifolia Benth., Brunfelsia pauciflora (Cham. \& Schlecht.) Benth., Capsicum flexuosum (L.) Sendtn., Capsicum villosum (L.) Sendtn., Cestrum amictum (L.) Schlecht., Cestrum corymbosum (L.) Schlecht., Cestrum lanceolatum (L.) Miers, Cestrum schlechtendalii (L.) G. Don, Cestrum sendtnerianum (L.) Mart. ex Sendtn., Cyphomandra diploconos Sendtn., Cyphomandra velutina Sendtn., Dyssochroma viridiflora (Sims) Ducke, Nicotiana langsdorffii (Weinm.) Roem. \& Schult., Physalis peruviana L., Physalis viscosa L., Sessea brasiliensis Tol., Solandra grandiflora Sw, Solanum americanum Mill., Solanum atropurpureum Schrank., Solanum bullatum Vell., Solanum capsicoides Allion., Solanum cernuum Vell., Solanum concinnum Schott ex Sendtn., Solanum didynum Dun., Solanum diflorum Vell., Solanum excelsum St. Hil. ex Dun., Solanum granuloso-leprosum Dun., Solanum hoehnei Morton, Solanum inaequale Vell., Solanum inodornum Vell., Solanum lycocarpum St. Hil. ex Dun., Solanum mauritianum Scop., Solanum paniculatum L., Solanum rufescens Sendtn., Solanum sisymbriifolium Lam., Solanum swartzianum Roem. \& Schult., Solanum vaillantii Dun., Solanum variabile Mart., Solanum viarum Dun. São apresentadas descrições para todas as espécies estudadas, ilustrações, observações e seis chaves polínicas. Palavras-chave: flora polínica, grãos de pólen, Solanaceae

\section{Introdução}

Este trabalho faz parte do projeto elaborado por Melhem et al. (1984), que visa realizar a caracteri- zação morfológica dos grãos de pólen das famílias ocorrentes na Reserva do Parque Estadual das Fontes do Ipiranga (PEFI), complementando assim os estudos taxonômicos realizados na mesma área, segundo

1. Instituto de Botânica, Caixa Postal 68041, 04045-972 São Paulo, SP, Brasil

2. Universidade Estadual Paulista, Faculdade de Ciências Agrárias e Veterinárias de Jaboticabal, Departamento de Biologia Aplicada à Agropecuária, Via de acesso Prof. Paulo Donato Castellane s/n, 14.884-900 Jaboticabal, SP, Brasil

3. Autor para correspondência: mcruzbarros@gmail.com 
planejamento apresentado por Melhem et al. (1981). O formato atual da Flora Polínica da Reserva segue Cruz-Barros \& Souza (2005).

A família Solanaceae está representada na Reserva, de acordo com Carvalho (1985) por 12 gêneros e 41 espécies: Acnistus Schott (A. arborescens (L.) Schlecht.), Athenaea Sendtn. (A. picta (Mart.) Sendtn.), Brunfelsia L. (B. latifolia Benth., B. pauciflora (Cham. \& Schlecht.) Benth.), Capsicum L. (C. flexuosum (L.) Sendtn., C. villosum (L.) Sendtn.), Cestrum L. (C. amictum (L.) Schlecht., C. corymbosum (L.) Schlecht., C. lanceolatum (L.) Miers, C. schlechtendalii (L.) G. Don, C. sendtnerianum (L.) Mart. ex Sendtn.), Cyphomandra Mart. ex Sendtn. (C. diploconos Sendtn., C. velutina Sendtn.), Dyssochroma Miers (D. viridiflora (Sims) Ducke), Nicotiana L. (N. langsdorffii (Weinm.) Roem. \& Schult.), Physalis L. (P. peruviana L., P. viscosa L.), Sessea R. \& P. (S. brasiliensis Tol.), Solandra Sw. (S. grandiflora Sw.), e Solanum L. (S. americanum Mill., S. atropurpureum Schrank., S. bullatum Vell., S. capsicoides Allion., S. cernuum Vell., S. concinnum Schott ex Sendtn., S. didynum Dun., S. diflorum Vell., S. excelsum St. Hil. ex Dun., S. granuloso-leprosum Dun., S. hoehnei Morton, S. inaequale Vell., $S$. inodornum Vell., S. lycocarpum St. Hil. ex Dun., S. mauritianum Scop., S. paniculatum L., S. rufescens Sendtn., S. sisymbriifolium Lam., S. swartzianum Roem. \& Schult., S. vaillantii Dun., S. variabile Mart., $S$. viarum Dun.).

Segundo dados da literatura, Solanaceae apresenta grãos de pólen em mônades ou tétrades, âmbito circular, triangular, oblatos a perprolatos, (2-)3(-4)5(-6)-colpados, colporoidados, 3(-4)-5-(6)-colporados, pantocolporados, sincolporados, parassincolpados, rugoroidados ou inaperturados; colpos longos ou curtos, estreitos ou largos; endoaberturas lalongadas, lolongadas, com áspide ou vestíbulo, pequeno ou não; exina psilada, perfurada, estriada, reticulada, microrreticulada, espiculosa, espinhosa, escabrada, verrugada, rugulada (Erdtman 1952, Natarajan 1957, Murry \& Eshbaugh 1971, Huang 1972, Salgado-Labouriau 1973, Rao \& Leong 1974, Wiebke \& Wiebke 1974, Anderson \& Gensel 1976, Punt \& Monna-Brands 1977, Roubik \& Moreno 1991, Persson et al. 1994, Batista-Franklim \& Gonçalves-Esteves 2002, 2008, Silva et al. 2003, Al-Quran 2004, Stafford \& Knapp 2006, Perveen \& Qaiser 2007, Barth \& Duarte 2008).

\section{Material e métodos}

O material botânico utilizado para a realização deste trabalho foi obtido, principalmente, a partir de botões florais de exsicatas depositadas no Herbário Científico do Estado "Maria Eneyda P. Kauffman Fidalgo" (SP). Em alguns casos, quando os materiais selecionados apresentavam-se em frutos ou com material polínico insuficiente, optou-se por coletas a partir de exsicatas provenientes de outras localidades. No caso do material G. Eiten et al. 5790 (SP140320), citado no inventário de Carvalho (1985), mas identificado apenas como Solanum sp., preferiu-se não incluí-lo no presente trabalho, uma vez que a ausência de uma identificação em nível específico impede a seleção de material adicional proveniente de outras localidades. A preparação dos grãos de pólen seguiu a técnica de acetólise de Erdtman (1960), acrescido das modificações citadas em Melhem et al. (2003). Para a espécie Brunfelsia latifolia Benth., devido à fragilidade dos seus grãos de pólen e consequentes deformações sofridas por eles, recorreu-se à técnica de acetólise láctica (Raynal \& Raynal 1971).

As ilustrações foram feitas em microscopia óptica, com grãos de pólen acetolisados e fotografados digitalmente utilizando-se fotomicroscópio Olympus BX 50 acoplado a uma câmara de vídeo e microcomputador (PC) e o programa Image Pro-Plus versão 3 para Windows.

A terminologia adotada está de acordo com Barth \& Melhem (1988) e Punt et al. (2007).

As lâminas com o material polínico encontram-se depositadas na palinoteca do Núcleo de Pesquisa em Palinologia do Instituto de Botânica.

\section{Resultados e Discussão}

\section{Acnistus Schott}

1. Acnistus arborescens (L.) Schlecht.

Figuras 1-2

Forma: oblato-esferoidal a prolato-esferoidal, âmbito subtriangular.

Aberturas: 3 cólporos, colpos longos, com margem; endoaberturas lalongadas, com extremidades afiladas; presença de fastígio não conspícuo.

Exina: finamente reticulado-estriada, sexina mais espessa que a nexina.

Medidas $(\mu \mathrm{m})$ : M.M.R.F. Melo \& S.L. Jung 76: $\mathrm{P}=24,1 \pm 0,3 ; \mathrm{E}=25,4 \pm 0,3 ;$ diâm. equatorial em vista 
polar $=24,2 \pm 0,4$; apocolpo ca. 4,4; cólporo compr. ca. 17,3, larg. ca. 3,5, margem ca. 2,9; endoabertura compr. ca. 4,3, larg. ca. 9,8; exina ca. 1,7, sexina ca. 1,2 , teto ca. 0,6 e nexina ca. 0,7 .

M. Kuhlmann s.n., SP43083: $\mathrm{P}=23,1 ; \mathrm{E}=21,7$; diâm. equatorial em vista polar $=21,9$.

F. Oliveira 10: $\mathrm{P}=27,3 ; \mathrm{E}=26,6$; diâm. equatorial em vista polar $=26,8$.

T. Sendulsky 982: $\mathrm{P}=29,3 ; \mathrm{E}=29,6$; diâm. equatorial em vista polar $=28,9$.

Observações: Os grãos de pólen de Acnistus arborescens foram estudados por Murry \& Eshbaugh (1971) que definiram a ornamentação dos grãos de pólen como reticulada, ao passo que nos espécimes aqui analisados ela é finamente reticulado-estriada. Murry \& Eshbaugh (1971) encontraram os seguintes valores para os diâmetros dos grãos de pólen dessa espécie: $\mathrm{P}=25,3 \mu \mathrm{m}$ (21-30) e $\mathrm{E}=23,0 \mu \mathrm{m}(20-27)$. Os valores dos espécimes aqui medidos encontram-se dentro da faixa de variação do material citado por estes autores. Barth \& Duarte (2008), ao estudarem os grãos de pólen de Acnistus arborescens, obtiveram resultados semelhantes aos encontrados no presente trabalho quanto às aberturas; no entanto, quantitativamente, os grãos de pólen descritos pelas autoras apresentaram diâmetros ligeiramente maiores $(\mathrm{P}=33,1 \mu \mathrm{m}(30-36)$ e $E=35,2 \mu \mathrm{m}(32-37))$ e a ornamentação foi definida como escabrada.

Material estudado: 18-IX-1940, M. Kuhlmann s.n. (SP43083); 6-XI-1978, M.M.R.F. Melo \& S.L. Jung 76 (SP); 13-X-1978, F. Oliveira 10 (SP); 12-VIII-1968, T. Sendulsky 982 (SP).

Athenaea Sendtn.

\section{Athenaea picta (Mart.) Sendtn.}

Figuras 3-5

Forma: prolato-esferoidal a subprolata, âmbito subtriangular.

Aberturas: 3 cólporos, colpos longos, estreitos, com margem e constrição mediana, recobertos por membrana ornamentada; endoaberturas lalongadas, com margem, constrição mediana e extremidades afiladas, recobertas por membrana levemente ornamentada; presença de fastígio conspícuo.

Exina: rugulado-reticulada.

Medidas $(\mu \mathrm{m}): F$. Oliveira 17: $\mathrm{P}=33,6 \pm 0,4$; $\mathrm{E}=32,6 \pm 0,4$; diâm. equatorial em vista polar $=33,3 \pm 0,4$; apocolpo ca. 8,4; cólporo larg. ca. 4,6, margem ca. 1,1; endoabertura compr. ca. 5,9, larg. ca. 21,5, margem ca. 1,4; exina 1,9, sexina ca. 1,3, teto ca. 0,6 e nexina ca. 0,7 .

T. Sendulsky 985: $\mathrm{P}=46,9 ; \mathrm{E}=39,5$; diâm. equatorial em vista polar $=37,6$.

Material estudado: 13-X-1970, F. Oliveira 17 (SP); 12-VIII-1968, T. Sendulsky 985 (SP).

\section{Brunfelsia L.}

Grãos de pólen com âmbito subcircular a subtriangular; prolato-esferoidais; 3-colporados, colpos longos, com margem e constritos na região mediana ou de difícil visualização; endoaberturas de difícil visualização, providas de fastígio ou não; exina estriada na região do pólo e estriado-reticulada na região do mesocólporo ou rugulada, com rúgulas tendendo a formar ínsulas, sexina mais espessa que a nexina.

\section{Brunfelsia latifolia Benth.}

Figuras 6

Forma: âmbito subcircular.

Aberturas: 3 cólporos, endoaberturas de difícil visualização.

Exina: rugulada, rúgulas tendendo a formar ínsulas.

Medidas $(\mu \mathrm{m}): \mathrm{P}=41,4 ; \mathrm{E}=40,8$; diâm. equatorial em vista polar $=34,9$.

Observações: O material da Reserva J.A. Corrêa 91 (SP), citado por Carvalho (1985), não foi estudado por falta de material polínico. Assim, foi estudado o material D. Sucre et al. 6428 (RB), proveniente de outra localidade. Devido à fragilidade dos grãos de pólen desta espécie e, consequentes deformações sofridas por eles, houve necessidade de recorrer-se à técnica de Raynal \& Raynal (1971); apesar disso, o material apresentou escassez de grãos de pólen não permitindo que se fizessem todas as medidas, dessa forma foram dadas apenas as médias aritméticas dos diâmetros. Os dados aqui obtidos para Brunfelsia latifolia confirmam a descrição de Batista-Franklim \& Gonçalves-Esteves (2002) quanto à abertura 3-colporada e ornamentação rugulada, embora no espécime aqui descrito, as rúgulas sejam nítidas, tendendo a formar ínsulas em algumas regiões e, no espécime descrito por Batista-Franklim \& Gonçalves-Esteves (2002) as rúgulas sejam menos conspícuas no mesocólporo. 
Material estudado:BRASIL. RIO DE JANEIRO: Restinga de Jacarepaguá, 27-XI-1969, D. Sucre et al. 6428 (RB).

2. Brunfelsia pauciflora (Cham. \& Schlecht.) Benth. Figuras 7-9

Forma: âmbito subtriangular

Aberturas: 3 cólporos; endoabertura lalongada de difícil visualização devido à constrição do cólporo, providas de fastígio.

Exina: estriada na região do pólo e estriado-reticulada na região do mesocólporoo, sexina mais espessa que a nexina.

Medidas $(\mu \mathrm{m})$ : Romaniuc Neto 49 (estame superior): $\mathrm{P}=47,6 \pm 0,5 ; \mathrm{E}=45,5 \pm 0,4$; diâm. equatorial em vista polar $=45,1 \pm 0,5$; apocolpo ca. 12,7 ; colpo compr. ca. 34,7 , larg. ca. 4,1 , margem ca. 1,8 ; exina ca. 2,1 , sexina ca. 1,3 , teto ca. 0,4 e nexina 0,8; (estame inferior): $\mathrm{P}=49,5+0,3 ; \mathrm{E}=46,2+0,7$; diam. equatorial em vista polar $=46,0 \pm 0,4$; apocolpo ca. 12,5; cólporo compr. ca. 40,3, larg. ca. 3,9, margem ca. 1,8 ; exina ca. 2,1 , sexina ca. 1,3 , teto ca. 0,4 e nexina ca. 0,8 .

F.C. Hoehne s.n., SP7953 (estame superior): $\mathrm{P}=50,0 ; \mathrm{E}=48,7 ;$ diâm. quatorial em vista polar $=49,5$; (estame inferior): $\mathrm{P}=48,9 ; \mathrm{E}=48,8$; diâm. equatorial em vista polar $=49,9$.

Observações: Os espécimes aqui analisados do gênero Brunfelsia apresentaram didinamia, por isso os grãos de pólen dos estamos superiores e inferiores da espécie $B$. pauciflora foram estudados separadamente. Foi possível separar pelo diâmetro polar (P), os grão de pólen dos estames superiores e inferiores. Os materiais da Reserva R. Faria 4 (SP), F.C. Hoehne s.n. (SP28167) e M.S.F. Silvestre 133 (SP), citados por Carvalho (1985), não foram estudados por possuírem apenas frutos, posteriormente, outros materiais da Reserva S. Romaniuc Neto 49 (SP) e F.C. Hoehne (SP7953) foram identificados como B. pauciflora e incluídos no presente estudo, visando uma melhor caracterização da espécie. Não foi possível comparar o tamanho dos grãos de pólen de Brunfelsia latifolia e B. pauciflora, porque foram utilizados métodos diferentes para a preparação dos mesmos. Stafford \& Knapp (2006) observaram para a espécie grãos de pólen ligeiramente menores que os aqui descritos ( $\mathrm{P}=34,0 \mu \mathrm{m}$ (31-35) e $\mathrm{E}=42,0 \mu \mathrm{m}$ (40-44); no entanto, os autores não fazem referência ao fenômeno de didinamia nem à procedência do pólen analisado (estame superior ou inferior). Outra divergência é que Stafford \&
Knapp (2006) descreveram a ornamentação dos grãos de pólen de B. pauciflora como rugulado-verrugada, o que não foi aqui confirmado.

Material estudado: 9-IX-1922, F.C. Hoehne s.n. (SP7953); 31-VIII-1982, S. Romaniuc Neto 49 (SP).

\section{Chave para as espécies de Brunfelsia}

1. Exina rugulada, rúgulas tendendo a formar ínsulas, âmbito subcircular .... B. latifolia

1. Exina estriada na região do pólo e estriado-reticulada na região do mesocólporo, âmbito subtriangular B. pauciflora

\section{Capsicum L.}

Grãos de pólen com âmbito circular a subtriangular; oblato-esferoidais, prolato-esferoidais a subprolatos; 3-colporados, cólpos longos, com margem, constritos na região mediana ou não; endoaberturas lalongadas, com extremidades truncadas ou bifidas, constrição mediana, providos de fastígio; exina granulada a rugulada; sexina mais espessa que a nexina.

\section{Capsicum flexuosum Sendtn.}

Figuras 10-11

Forma: prolato-esferoidal a subprolata, âmbito circular.

Aberturas: 3 cólporos, colpos sem constrição; endoabertura com constrição mediana e com extremidades truncadas.

Exina: exina rugulada.

Medidas $(\mu \mathrm{m})$ : $O$. Handro 2177: $\mathrm{P}=30,7 \pm 0,4$; $\mathrm{E}=30,2 \pm 0,4$; diâm. equatorial em vista polar $30,3 \pm 0,4$; apocolpo ca. 7,8; cólporo compr. ca. 23,0, larg. ca. 3,6, margem ca. 1,6; endoabertura compr. ca. 5,1 ; exina ca. 1,6 , sexina ca. 1,0 , teto ca. 0,4 , e nexina 0,6 .

T.M. Cerati 7: $\mathrm{P}=26,6$; diâm. equatorial em vista polar $=32,2$

M. Kuhlmann s.n., SP49458: $\mathrm{P}=28,2 ; \mathrm{E}=25,2 ;$ diâm. equatorial em vista polar $=31,1$.

I.C.C. Macedo 5: $\mathrm{P}=26,0: \mathrm{E}=22,2$; diâm. equatorial em vista polar $=31,6$.

Observações: Os materiais F. Barros 533 (SP), S.L. Jung \& F. Barros 374 (SP) e J.F. Toledo \& M. Kuhlmann s.n. (SP50327) citados por Carvalho (1985) não foram estudados por escassez de material polínico ou por possuírem apenas frutos. 
Material estudado: 10-IX-1982, T.M. Cerati 7 (SP); 4-XI-1971, O. Handro 2177 (SP); 5-XI-1943, M. Kuhlmann s.n. (SP49458); 3-II-1983, I.C.C. Macedo 5 (SP).

\section{Capsicum villosum Sendtn.}

Figuras 12-13

Forma: oblato-esferoidal a prolato-esferoidal, âmbito subtriangular.

Aberturas: 3 cólporos, colpos constritos na região mediana; endoabertura com extremidades bífidas.

Exina: granulada.

Medidas ( $\mu \mathrm{m})$ : M. Kuhlmann s.n., SP52077: $\mathrm{P}=29,6 \pm 0,3 ; \mathrm{E}=30,9 \pm 0,3 ;$ diâm. equatorial em vista polar 28,3; apocolpo ca. 6,0; cólporo compr. ca. 23,2 larg. ca. 3,2, margem ca. 1,4; endoabertura compr. ca. 6,0, larg. ca. 20,3; exina ca. 1,5, sexina ca. 1,1 , teto ca. 0,3 e nexina ca. 0,4 .

J. Mattos 12165: $\mathrm{P}=32,8 ; \mathrm{E}=31,6$ : diâm. equatorial em vista polar $=30,8$.

J. Vasconcellos Neto 6813: $\mathrm{P}=29,2 ; \mathrm{E}=29,9$; diâm. equatorial em vista polar $=28,6$.

Observações: Os materiais J.S. Silva 272 (SP) e M. Kuhlmann 3556 (SP) citados por Carvalho (1985), não foram estudados, pois no primeiro, os grãos de pólen estavam amassados, enquanto no segundo o material estava em estado de frutificação.

Material estudado: 14-III-1944, M. Kuhlmann s.n. (SP52077); 13-XII-1964, J. Mattos 12165 (SP); 5-I-1978, J. Vasconcellos Neto s.n. (SP154835).

\section{Chave para as espécies de Capsicum}

1. Exina rugulada, colpos não constritos na região mediana, endoabertura com extremidades truncadas .... C. flexuosum

1. Exina granulada, colpos constritos na região mediana, endoabertura com extremidades bífidas C. villosum

\section{Cestrum L.}

Grãos de pólen com âmbito subcirclar, oblatoesferoidais a prolato-esteroidais; 3(-4)-cólporados, colpos longos, recobertos por uma membrana ornamentada ou não, com margem; endoabertura lalongada, com extremidades arredondadas, afiladas ou truncadas, com leve constrição mediana ou sem, providas de fastígio; exina rugulada, rugulado-estriada, estriada na região do mesocólporo e rugulado-estriada na região polar ou rugulada, na região do mesocólporo e rugulado-estriada na região polar rugulada, sexina mais espessa que a nexina.

\section{Cestrum amictum Schlecht.}

Figuras 14-15

Forma: oblato-esferoidal a prolato-esferoidal.

Abertura: 3(-4) cólporos, colpos recobertos por uma membrana ornamentada, com margem; endoabertura lalongada, com extremidades afiladas.

Exina: rugulado-estriada.

Medidas $(\mu \mathrm{m})$ : O. Handro s.n., SP37596: $\mathrm{P}=43,6 \pm 0,3 ; \mathrm{E}=44,0 \pm 0,4$, diâm. equatorial em vista polar $=44,3 \pm 0,5$; apocolpo ca. 10,1 ; cólporo compr. ca. 36,1, larg. ca. 5,6, margem ca. 1,6; endoabertura compr. ca. 6,7, larg. ca. 23,6; exina ca. 2,1 , sexina ca. 1,2 , teto ca. 0,5 e nexina ca. 0,7 .

S.L. Jung et al. 227: P =41,0; $\mathrm{E}=41,8$; diâm. equatorial em vista polar $=40,8$.

S.L. Jung et al. 231: $\mathrm{P}=35,9 ; \mathrm{E}=36,9$; diâm. equatorial em vista polar $=42,4$.

M. Kirizawa 184: $\mathrm{P}=35,6 ; \mathrm{E}=33,9$; diâm. equatorial em vista polar $=34,8$.

M. Kuhlmann 3889: $\mathrm{P}=37,9 ; \mathrm{E}=38,5$; diâm. equatorial em vista polar $=43,9$.

Observações: Os materiais da Reserva, S.L. Jung et al. 45 (SP), M. Kirizawa 420 (SP), H. Makino 85 (SP), H. Makino 125 (SP), M.M.R.F. Melo et al. 59 (SP), M.M.R.F. Melo et al. 128 (SP) e M.S.F. Silvestre 13 (SP), citados por Carvalho (1985), não foram estudados por escassez de material polínico ou por possuirem apenas frutos. Para o espécime de herbário aqui estudado O. Handro s.n. (SP37596), constatou-se a presença de grãos de pólen com 4 aberturas (2\%). Os grãos de pólen da espécie, também foram analisados palinologicamente por Silva et al. (2003), que definiram a ornamentação como estriada e com diâmetros consideravelmente menores $[\mathrm{P}=30,3 \mu \mathrm{m}(25-32)$ e $\mathrm{E}=30,4 \mu \mathrm{m}(20-35)]$ que os cinco espécimes aqui analisados.

Material estudado: 7-I-1937, O. Handro s.n. (SP37596); 13-XI-1978, S.L. Jung et al. 227 (SP); 13-XI-1978, S.L. Jung et al. 231 (SP); 9-III-1978, M. Kirizawa 184 (SP); 13-I-1956, M. Kuhlmann 3889 (SP).

\section{Cestrum corymbosum Schlecht}

Figuras 16-18

Forma: oblato-esferoidal a prolato-esferoidal.

Aberturas: 3 cólporos, endoaberturas lalongadas, com extremidades afiladas. 

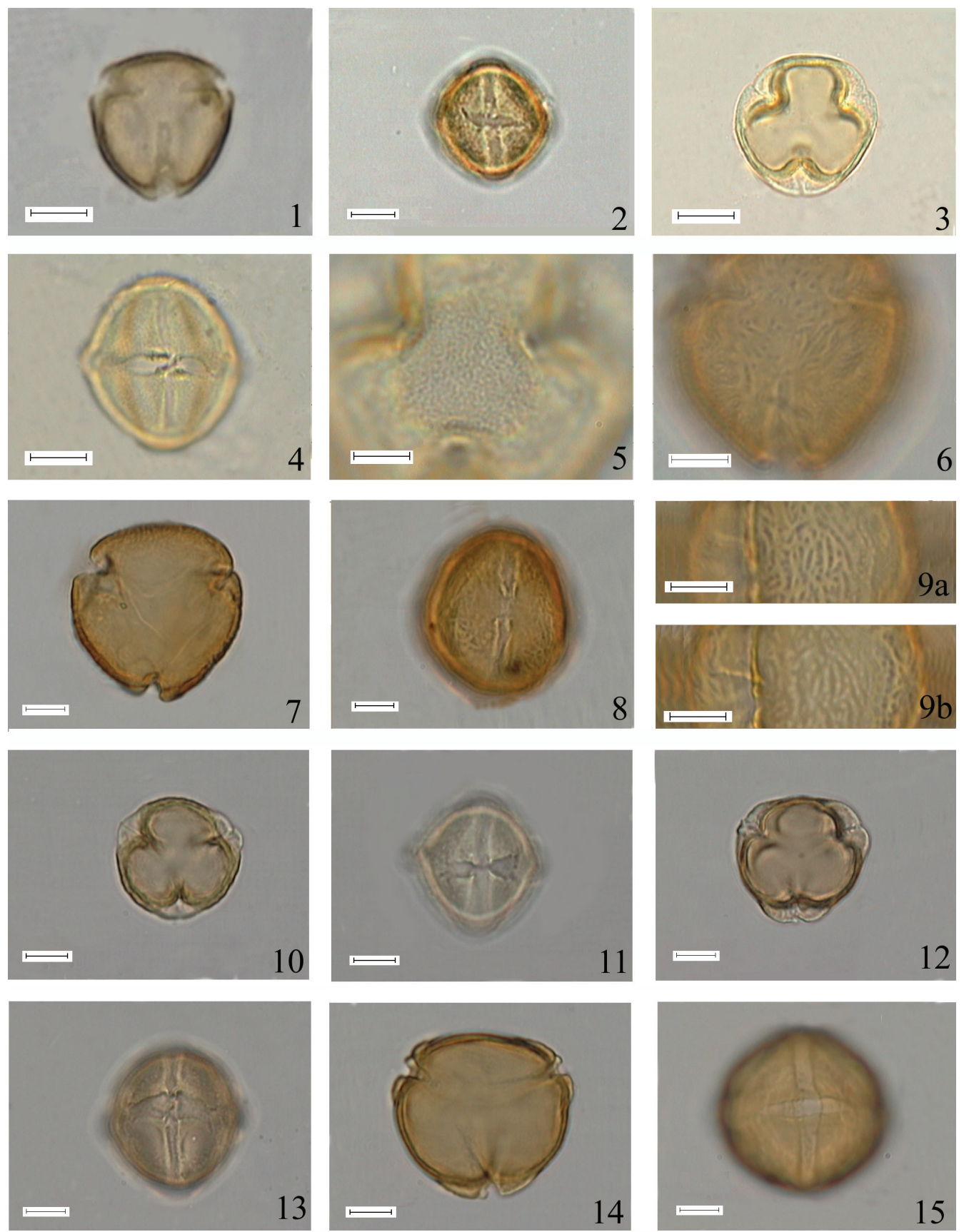

Figuras 1-15. Fotomicrografias dos grãos de pólen dos gêneros Acnistus, Athenaea, Brunfelsia, Capsicum e Cestrum (Solanaceae). Figuras 1-2. Acnistus arborescens (L.) Schlecht. 1. Vista polar. 2. Vista equatorial evidenciando o cólporo. Figuras 3-5. Athenaea picta (Mart.) Sendtn. 3. Vista polar. 4. Vista equatorial. 5. Vista polar evidenciando a ornamentação. Figura 6. Brunfelsia latifolia Benth, vista polar evidenciando a ornamentação. Figuras 7-9. Brunfelsia pauciflora (Cham. \& Schlecht.) Benth. 7. Vista polar. 8. Vista equatorial. 9. L.O. em dois níveis de focalização. Figuras 10-11. Capsicum flexuosum (L.) Sendtn. 10. Vista polar. 11. Vista equatorial evidenciando o cólporo. Figuras 12-13. Capsicum villosum (L.) Sendtn. 12. Vista polar. 13. Vista equatorial evidenciando o cólporo. Figuras 14-15. Cestrum amictum (L.) Schlecht. 14. Vista polar. 15. Vista equatorial. Barras da escala $=5 \mu \mathrm{m}(5,8,9) ; 10 \mu \mathrm{m}(1-4,6-7,10-15)$.

Figures 1-15. Photomicrographs of pollen grains of genera Acnistus, Athenaea, Brunfelsia, Capsicum and Cestrum (Solanaceae). Figures 1-2. Acnistus arborescens (L.) Schlecht. 1. Polar view. 2. Equatorial view showing aperture. Figures 3-5. Athenaea picta (Mart.) Sendtn. 3. Polar view. 4. Equatorial view. 5. Polar view showing ornamentation. Figure 6. Brunfelsia latifolia Benth, polar view showing ornamentation. Figures 7-9. Brunfelsia pauciflora (Cham. \& Schlecht.) Benth. 7. Polar view. 8. Equatorial view. 9. L.O. in high and low focus. Figures 10-11. Capsicum flexuosum (L.) Sendtn. 10. Polar view. 11. Equatorial view showing aperture. Figures 12-13. Capsicum villosum (L.) Sendtn. 12. Polar view. 13. Equatorial view showing aperture. Figures 14-15. Cestrum amictum (L.) Schlecht. 14. Polar view. 15. Equatorial view. $\operatorname{Bar}=5 \mu \mathrm{m}(5,8,9) ; 10 \mu \mathrm{m}(1-4,6-7,10-15)$. 
Exina: estriada na região do mesocólporo e rugulado-estriada na região polar.

Medidas $(\mu \mathrm{m})$ : O. Handro s.n., SP31037: $\mathrm{P}=45,4 \pm 0,3 ; \mathrm{E}=44,9 \pm 0,3 ;$ diâm. equatorial em vista polar $=45,3 \pm 0,4$; apocolpo ca. 11,7 ; cólporo compr. ca. 35,7 , larg. ca. 6,3, margem ca. 1,9; endoabertura compr. ca. 4,7, larg. ca. 26,8; exina ca. 2,2 , sexina ca. 1,6 , teto ca. 0,6 e nexina ca. 0,7 .

O.G. Fonseca s.n., SP113826: $\mathrm{P}=37,5: \mathrm{E}=38,5$; diâm. equatorial em vista polar $=37,5$.

Material estudado: 10-I-1968, O.G. Fonseca s.n. (SP113826); 22-IX-1933, O. Handro s.n. (SP31037).

\section{Cestrum lanceolatum Miers}

Figuras 19-20

Forma: prolato-esferoidal.

Aberturas: 3 cólporos, endoaberturas lalongadas, com extremidades afiladas.

Exina: rugulada.

Medidas $(\mu \mathrm{m})$ : D.B.I. Pickel s.n., SP299897: $\mathrm{P}=38,2 \pm 0,4 ; \mathrm{E}=36,1 \pm 0,4 ;$ diâm. equatorial em vista polar $=35,6 \pm 0,3$; apocolpo ca. 10,7; cólporo compr. ca. 30,0, larg. ca. 3,1, margem ca. 1,1; endoabertura compr. ca. 8,0, larg. ca. 30,8; exina ca. 2,5, sexina ca. 1,7 , teto ca. 0,9 e nexina ca. 0,7 .

Observações: Os materiais da Reserva J.A. Corrêa 29 (SP) e J.S. Silva 284 (SP), citados por Carvalho (1985), não foram estudados por possuírem apenas frutos, dessa forma foi estudado o material D.B.I. Pickel s.n. (SP299897) proveniente de outra localidade. Os dados aqui obtidos corroboram os de Silva et al. (2003) para os grãos de pólen de C. lanceolatum (tamanho, forma, âmbito e aberturas), no entanto os autores descrevem sua ornamentação como verrucada e não rugulada como aqui observado.

Material estudado: BRASIL. São PAULO: São Paulo, Chácara dos Morrinhos, 30-IV-1942, D.B.I. Pickel s.n. (SP299897).

\section{Cestrum schlechtendalii G.Don}

Figuras 21-22

Forma: prolato esferoidal.

Aberturas: 3(-4) cólporos; endoabertura lalongada, com constrição mediana, extremidades truncadas.

Exina: rugulada.

Medidas $(\mu \mathrm{m})$ : F.C. Hoehne s.n., SP29714: $\mathrm{P}=41,2 \pm 0 ; 5 ; \mathrm{E}=38,9 \pm 0,4 ;$ diâm. equatorial em vista polar $=39,9 \pm 0,3$; apocolpo ca. 10,5 ; cólporo compr. ca. 31,7 , larg. ca. 3,1, margem ca. 0,9 ; endoabertura compr. ca. 7,2, larg. ca. 33,2; exina ca. 2,1 sexina ca. 1,4 , teto ca. 0,7 e nexina ca. 0,7 .

M.M.R.F. Melo 250: $\mathrm{P}=36,5 ; \mathrm{E}=34,7$; diâm. equatorial em vista polar $=35,0$.

Observações: Para o espécime de herbário aqui estudado, F.C. Hoehne s.n. (SP29714), constatou-se a presença de grãos de pólen com 4 aberturas (1\%). Outro material da Reserva, M.R.F. Melo 250 (SP), foi identificado como C. schlechtendalii e incluído no presente estudo, visando uma melhor caracterização da espécie. Silva et al. (2003), ao estudarem os grãos de pólen da espécie, observaram grãos de pólen relativamente menores $(\mathrm{P}=36,1 \mu \mathrm{m}(32-40) \mathrm{e}$ $\mathrm{E}=29,1 \mu \mathrm{m}$ (22-32), subprolatos, com ornamentação perfurado-escabrada, divergindo desta forma, dos resultados aqui obtidos.

Material estudado: 3-VI-1932, F.C. Hoehne s.n. (SP29714); 13-V-1981, M.R.F. Melo 250 (SP).

\section{Cestrum sendtnerianum Mart. ex Sendtn.}

Figuras 23-24

Forma: oblato-esferoidal.

Aberturas: 3 cólporos, recobertos por uma membrana ornamentada; endoaberturas lalongadas, com extremidades arredondadas.

Exina: exina rugulada, na região do mesocólporo, rugulado-estriada na região polar.

Medidas ( $\mu \mathrm{m})$ : S.L. Jung 292A: $\mathrm{P}=40,9 \pm 0,3 ;$ $\mathrm{E}=41,1 \pm 0,4$; diâm. equatorial em vista polar $=41,7 \pm 0,3$; apocolpo ca. 12,8 ; cólporo compr. ca. 31,3, larg. ca. 4,1, margem ca. 0,9; endoabertura compr. ca. 7,2, larg. ca. 33,2; exina ca. 2,1, sexina ca. 1,4 , teto ca. 0,7 e nexina ca. 0,7 .

J.S. Silva 304: $\mathrm{P}=36,3 ; \mathrm{E}=36,2$; diâm. equatorial em vista polar $=36,0$.

Observações: O material W.G.D'Arcy 10438 (SP), citado por Carvalho (1985), não foi estudado pois os grãos de pólen eram escassos e amassados. Outro material da Reserva, J.S. Silva 304 (SP), foi identificado como C. sendtnerianum e incluído no presente estudo, visando uma melhor caracterização da espécie. Para Silva et al. (2003), os grãos de pólen de $C$. sendtnerianum, apresentaram forma esférica e ornamentação estriada, o que não foi observado no presente estudo.

Material estudado: 5-X-1979, S.L. Jung 292A (SP); 28-V-1974, J.S. Silva 304 (SP). 
Chave para as espécies de Cestrum

1. Endoaberturas com extremidades afiladas

2. Exina estriada na região do mesocólporo C. corymbosum

2. Exina rugulada ou rugulado-estriada na região do mesocólporo

3. Exina rugulado-estriada na região do mesocólporo, colpos com membrana ornamentada . C. amictum

3. Exina rugulada na região do mesocólporo, colpos sem membrana ornamentada C. lanceolanum

1. Endoaberturas com extremidades truncadas ou arredondadas

4. Endoaberturas com extremidades truncadas e com constrição mediana C. schlechtendalii

4. Endoaberturas com extremidades arredondadas e sem constrição mediana C. sendtnerianum

Cyphomandra Mart. ex Sendtn.

Grãos de pólen com âmbito subcircular a subtriangular; oblato-esferoidais, prolato-esferoidais a subprolatos, 3-colporados, colpos longos, estreitos, recobertos por membrana ornamentada, com margem; endoaberturas lalongadas, extremidades arredondadas ou truncadas, recobertas por membrana ornamentada, com margem, com constrição mediana, providas de fastígio; exina escabrada a rugulada, sexina mais espessa que a nexina.

O gênero é representado na Reserva por duas espécies: C. diploconos Sendtn. e C. velutina Sendtn.

\section{Cyphomandra diploconos Sendtn.}

Figuras 25-26

Forma: prolato-esferoidal a subprolata, âmbito subcircular.

Abertura: endoabertura com extremidades truncadas.

Exina: escabrada.

Medidas $(\mu \mathrm{m})$ : M.S.F. Silvestre 215: $\mathrm{P}=34,4 \pm 0,5 ; \mathrm{E}=29,4 \pm 0,5 ;$ diâm. equatorial em vista polar $=29,7 \pm 0,2$; apocolpo ca. 9,3; cólporo larg. ca. 3,2, margem ca. 1,6; endoabertura compr. ca. 6,5 , margem ca. 1,6 ; exina ca. 1,6 , sexina ca. 1,2 , teto ca. 0,5 e nexina ca. 0,5 .

J. Mattos 12661: $\mathrm{P}=27,1 ; \mathrm{E}=25,8$; diâm. equatorial em vista polar $=26,4$.
T. Sendulsky 1167: $\mathrm{P}=23,2 ; \mathrm{E}=22,3$; diâm. equatorial em vista polar $=24,2$.

Observações: Os materiais F. Barros 596 (SP) e R.P. de Lyra 67 (SP), citados por Carvalho (1985) ,não foram estudados por apresentarem grãos de pólen amassados.

Material estudado: 5-I-1965, J. Mattos 12661 (SP); 11-XI-1970, T. Sendulsky 1167 (SP); 28-XI-1979, M.S.F. Silvestre 215 (SP).

\section{Cyphomandra velutina Sendtn.}

Figuras 27-28

Forma: prolato-esferoidal, âmbito subtriangular.

Abertura: endoabertura com extremidades arredondadas.

Exina: rugulada.

Medidas $(\mu \mathrm{m}): \mathrm{P}=26,9 \pm 0,2 ; \mathrm{E}=25,6 \pm 0,2 ;$ diâm. equatorial em vista polar $=25,5 \pm 0,3$; apocolpo ca. 6,6; cólporo larg. ca. 3,8, margem ca. 1,1; endoabertura compr. ca. 5,9, margem ca. 1,3; exina ca. 1,3 , sexina ca. 0,9 , teto ca. 0,4 e nexina ca. 0,5 .

Material estudado: 23-XI-1932, O. Handro s.n. (SP29944).

\section{Chave para as espécies de Cyphomandra}

1. Grãos de pólen com exina rugulada, endoabertura com extremidades arredondadas C. velutina

1. Grãos de pólen com exina escabrada, endoabertura com extremidades truncadas C. diploconos

\section{Dyssochroma Miers}

\section{Dyssochroma viridiflora (Sims) Ducke}

Figuras 29-31

Forma: suboblata, âmbito subtriangular.

Aberturas: 3 cólporos, colpos longos, estreitos, recobertos por membrana esculturada, com margem; endoaberturas lalongadas, extremidades arredondadas, recobertas por membrana esculturada, com margem, presença de fastígio não conspícuo.

Exina: microrreticulada na região polar e reticulado-estriada na região do mesocólporo, sexina mais espessa que a nexina.

Medidas $(\mu \mathrm{m}): \mathrm{P}=36,9 \pm 0,4 ; \mathrm{E}=45,9 \pm 0,4$; diâm. equatorial em vista polar $=44,9 \pm 0,4$; apocolpo ca. 15,6; cólporo larg. ca. 2,1, margem ca. 1,2; 

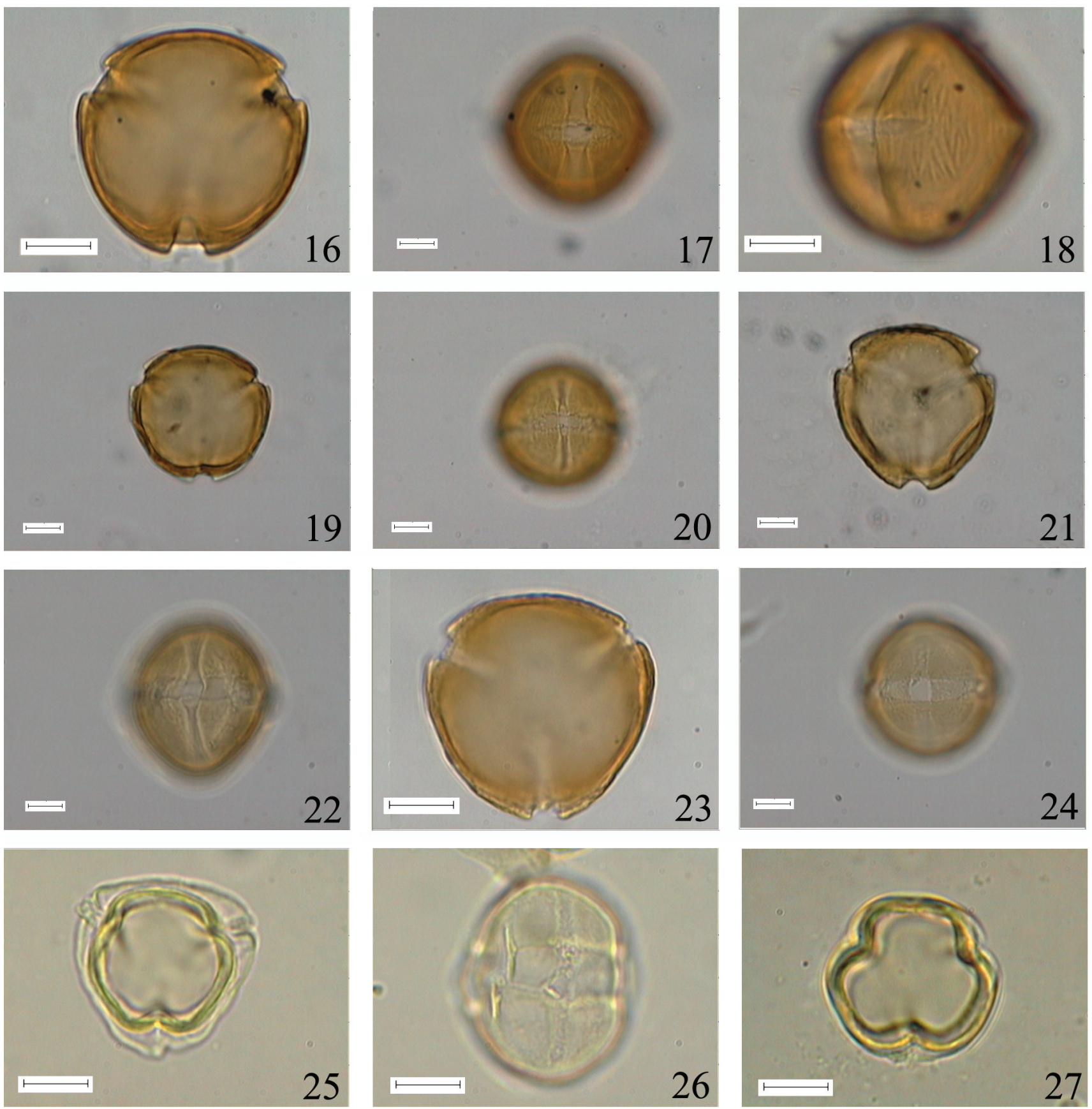

Figuras 16-27. Fotomicrografias dos grãos de pólen dos gêneros Cestrum e Cyphomandra (Solanaceae). Figuras 16-18. Cestrum corymbosum (L.) Schlecht. 16. Vista polar. 17. Vista equatorial. 18. Vista equatorial evidenciando a ornamentação no mesocólporo. Figuras 19-20. Cestrum lanceolatum (L.) Miers 19. Vista polar. 20. Vista equatorial evidenciando o cólporo. Figuras 21-22. Cestrum schlechtendalii (L.) G. Don. 21. Vista polar. 22. Vista equatorial. Figuras 23-24. Cestrum sendtnerianum (L.) Mart. ex Sendtn. 23. Vista polar. 24. Vista equatorial. Figuras 25-26. Cyphomandra diploconos Sendtn. 25. Vista polar. 26. Vista equatorial evidenciando o cólporo. Figura 27. Cyphomandra velutina Sendtn., vista polar. Barras da escala $=10 \mu \mathrm{m}$.

Figures 16-27. Photomicrographs of pollen grains of genera Cestrum e Cyphomandra (Solanaceae). Figures 16-18. Cestrum corymbosum (L.) Schlecht. 16. Polar view. 17. Equatorial view. 18. Equatorial view showing ornamentation in the mesocolpore. Figures 19-20. Cestrum lanceolatum (L.) Miers 19. Polar view. 20. Equatorial view showing aperture. Figures 21-22. Cestrum schlechtendalii (L.) G. Don. 21. Polar view. 22. Equatorial view. Figures 23-24. Cestrum sendtnerianum (L.) Mart. ex Sendtn. 23. Polar view. 24. Equatorial view. Figures 25-26. Cyphomandra diploconos Sendtn. 25. Polar view. 26. Equatorial view showing aperture. Figure 27. Cyphomandra velutina Sendtn., polar view. Bar $=10 \mu \mathrm{m}$. 
endoabertura compr. ca. 6,8, larg. ca. 21,7, margem ca. 1,2 ; exina ca. 2,2 , sexina ca. 1,6 , teto ca. 0,6 e nexina ca. 0,7 .

Material estudado: 12-VII-1956, M. Kuhlmann et al. s.n. (SP154296).

Observações: Os grãos de pólen de $D$. viridiflora foram também analisados por Persson et al. (1994). Os autores descreveram grãos de pólen suboblatos como os aqui estudados, no entanto citaram uma ornamentação reticulada (no equador e nos pólos) com muros descontínuos no mesocólporo.

\section{Nicotiana L.}

\section{Nicotiana langsdorffii Weinm.}

Figuras 32-34

Forma: prolato-esferoidal, âmbito circular.

Aberturas: 3 cólporos, colpos longos, estreitos, recobertos por membrana ornamentada, com margem, constritos; endoabertura lalongada de difícil visualização.

Exina: microrreticulada, sexina mais espessa que a nexina.

Medidas $(\mu \mathrm{m}): \mathrm{P}=35,7 \pm 0,4 ; \mathrm{E}=33,1 \pm 0,4$; diâm. equatorial em vista polar $=33,5 \pm 0,4$; apocolpo ca. 6,6; cólporo larg. ca. 7,2, margem ca. 1,5; endoabertura compr. ca. 4,2, larg. ca. 8,4; exina ca. 1,6 , sexina ca. 1,0 , teto ca. 0,4 e nexina ca. 0,6 .

Observações: Não foi possível medir o comprimento do colpo, por este ser muito longo. O material $F$. Oliveira 9 (SP), citado por Carvalho (1985), não foi estudado por apresentar grãos de pólen amassados.

Material estudado: 7-XII-1970, T. Sendulky 1164 (SP).

\section{Physalis L.}

Grãos de pólen com âmbito subtriangular; oblato-esferoidais a prolato-esferoidais; 3-colporados, colpos longos, estreitos, recobertos por membrana ornamentada, com margem; endoabertura lalongada, extremidades afiladas, com margem, com constrição mediana ou não; presença de fastígio conspícuo; exina microrreticulada a rugulada; sexina mais espessa que a nexina.

O gênero é representado, na Reserva, por duas espécies: $P$. peruviana L e $P$. viscosa L.

\section{Physalis peruviana $\mathrm{L}$.}

Figuras 35-37

Forma: prolato-esferoidal.

Aberturas: endoabertura com constrição mediana. Exina: microrreticulada.

Medidas $(\mu \mathrm{m}): \mathrm{P}=33,8 \pm 0,2 ; \mathrm{E}=32,3 \pm 0,4 ;$ diâm. equatorial em vista polar $=32,1 \pm 0,3$; apocolpo ca. 6,5 ; cólporo larg. ca. 4,9, margem ca. 1,2; endoabertura compr. ca. 5,7, larg. ca. 20,8, margem ca. 1,4 ; exina ca. 2,1 , sexina ca. 1,4 , teto ca. 0,5 e nexina ca. 0,7 .

Observações: Os materiais da Reserva J.S. Silva s.n. (SP167825) e B. Skvortzov s.n. (SP105672), citados por Carvalho (1985) como Physalis pubescens L., correspondem à espécie $P$. peruviana L., mas apresentaram grãos de pólen amassados, por isso foi estudado o material A.S. Costa s.n. (SP43603) proveniente de outra localidade. Os grãos de pólen aqui estudados apresentaram ocasionalmente cólporos muito longos unidos nos pólos, parecendo parassincolpados por causa do rompimento da área polar muito reduzida. Foram também encontrados grãos de pólen com endoaberturas tão longas que as extremidades de duas endoaberturas adjacentes se sobrepõem parecendo aberturas endocinguladas (figura 37).

Material estudado: BRASIL. São PAulo: Cunha, 22-XI-1938, A.S. Costa s.n. (SP43603).

\section{Physalis viscosa L.}

Figuras 38-39

Forma: oblato-esferoidal.

Aberturas: endoaberturas sem constrição mediana.

Exina: rugulada.

Medidas $(\mu \mathrm{m}): \mathrm{P}=26,1 \pm 0,2 ; \mathrm{E}=26,6 \pm 0,2 ;$ diâm. equatorial em vista polar $=26,7 \pm 0,1$; apocolpo ca. 3,5; cólporo larg. ca. 3,3; endoabertura compr. ca. 3,8 , larg. ca. 16,0 , margem ca. 1,3 ; exina ca. 1,5 , sexina ca. 0,9 , teto ca. 0,4 e nexina ca. 0,6 .

Observações: Murry \& Eeshbaugh (1971), ao estudarem Physalis viscosa, descreveram os grãos de pólen como tricolporados, ocasionalmente parassincolporados, e com ornamentação reticulada, ao passo que no espécime aqui estudado os grãos de pólen são 3-cólporados e com ornamentação rugulada

Material estudado: 10-VII-1975, M. Sakane 326 (SP). 
Chave para as espécies de Physalis

1. Grãos de pólen prolato-esferoidais, exina microrreticulada, endoaberturas com constrição mediana P. peruviana

1. Grãos de pólen oblato-esferoidais, exina rugulada, endoaberturas sem constrição mediana P. viscosa

Sessea Ruiz \& Pav.

\section{Sessea brasiliensis Tol.}

Figuras 40-41

Forma: subprolata, âmbito circular.

Aberturas: 3 cólporos, colpos longos, estreitos, com margem e constritos; endoaberturas lalongadas, constritas, com extremidades ligeiramente arredondadas, presença de fastígio não conspícuo.

Exina: escabrada, sexina mais espessa que a nexina.

Medidas $(\mu \mathrm{m}): \mathrm{P}=35,8 \pm 0,4 ; \mathrm{E}=28,5 \pm 0,3$; diâm. equatorial em vista polar ca. 28,1; apocolpo ca. 4,2; cólporo larg. ca. 3,9, margem ca. 1,2; endoabertura compr. ca. 3,8, larg. ca. 16,0, margem ca. 0,8 ; exina ca. 1,8 , sexina ca. 1,3 , teto ca. 0,6 e nexina ca. 0,6 .

Observações: O material F.C. Hoehne s.n. (SP29746), citado por Carvalho (1985), não foi estudado por escassez de material polínico.

Material estudado: 31-V-1961, A. Hodgson s.n. (SP117055).

\section{Solandra Sw.}

\section{Solandra grandiflora Sw.}

Figuras 42-45

Forma: oblato-esferoidal, âmbito circular.

Aberturas: 3 cólporos, colpos curtos, estreitos, brevicolporados, endoaberturas lalongadas de difícil visualização.

Exina: reticulada, heterorreticulada, muros curvos, sexina mais espessa que a nexina.

Medidas $(\mu \mathrm{m}): \mathrm{P}=30,5 \pm 0,3 ; \mathrm{E}=32,0 \pm 0,2 ;$ diâm. equatorial em vista polar $=31,8 \pm 0,3$; exina ca. 2,2, sexina ca. 1,5 , teto ca. 0,7 e nexina ca. 0,7 .

Observações: Não foi possível medir o colpo e a endoabertura devido a pouca visibilidade dos seus limites. Trigo (1992) encontrou os seguintes valores para os diâmetros dos grãos de pólen de $S$. grandiflora $\mathrm{P}=18,72 \pm 0,59 \mu \mathrm{m}(17-19 \mu \mathrm{m})$ e $\mathrm{E}=20,26 \pm 0,65 \mu \mathrm{m}$
(19-21 $\mu \mathrm{m})$. O espécime aqui analisado possui grãos de pólen com diâmetros maiores.

Material estudado: 15-I-1952, O. Handro 287 (SP).

\section{Solanum L.}

Grãos de pólen com âmbito elíptico, circular, subcircular, subtriangular; oblato-esferoidais, prolato-esferoidais a subprolatos; (2-)3(-4)-colporados, colpos longos, ou curtos, estreitos, recobertos por uma membrana ornamentada, com constrição mediana ou não, com margem ou não; endoabertura lalongada, com constrição mediana ou não, com extremidades afiladas, arredondadas, truncadas ou endocingulo (endoabertura lalongada formando um anel ao redor do grão de pólen) providas de fastígio; exina psilada, escabrada, microrreticulada, rugulada; sexina mais espessa que a nexina.

O gênero é representado na Reserva por 22 espécies: S. americanum Mill., S. atropurpureum Schrank., S. bullatum Vell., S. capsicoides Allion., S. cernuum Vell., S. concinnum Schott ex Sendtn., $S$. didynum Dun., S. diflorum Vell., S. excelsum St. Hil. ex Dun., S. granuloso-leprosum Dun., S. hoehnei Morton, S. inaequale Vell., S. inodornum Vell., S. lycocarpum St. Hil. ex Dun., S. mauritianum Scop., S. paniculatum L., S. rufescens Sendtn., S. mauritianum Scop., S. sisymbriifolium Lam., S. swartzianum Roem. \& Schult., S. vaillantii Dun., $S$. variabile Mart. e $S$. viarum Dun.

\section{Solanum americanum Mill.}

Figuras 46-47

Forma: oblato-esferoidal, prolato-esferoidal a subprolata, âmbito subcircular.

Aberturas: 3 cólporos, colpos longos, com leve constrição mediana, com margem; endoaberturas lalongadas, com constrição mediana e extremidades truncadas, providas de fastígios conspícuos.

Exina: escabrada.

Medidas $(\mu \mathrm{m})$ : M. Kuhlmann s.n., SP154574: $\mathrm{P}=20,9 \pm 03 ; \mathrm{E}=21,2 \pm 02$; diâm. equatorial em vista polar $=20,4 \pm 0,2$; apocolpo ca. 2,9; cólporo compr. ca. 16,6, larg. ca. 1,9; endoabertura compr. ca. 2,3, larg. ca. 8,5 ; exina ca. 1,7 , sexina ca. 1,0 , teto ca. 0,5 e nexina ca. 0,7 .

G. Davidse \& W.G. D'Arcy 10487: $\mathrm{P}=20,8$; $\mathrm{E}=19,9$; diâm. equatorial em vista polar $=20,8$.

M. Kirizawa 414: $\mathrm{P}=19,9 ; \mathrm{E}=18,4$; diâm. equatorial em vista polar $=19,0$. 

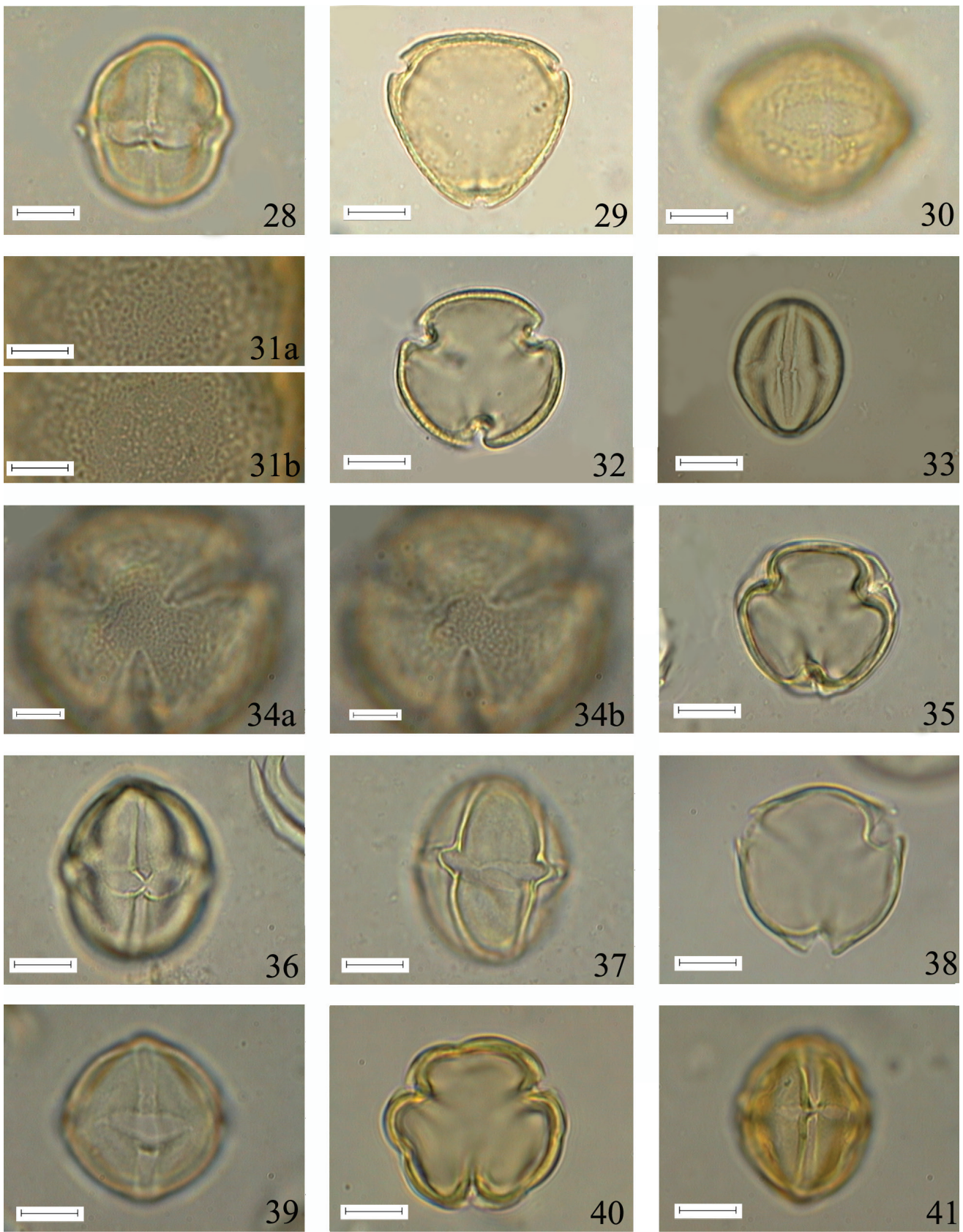

Figuras 28-41. Fotomicrografias dos grãos de pólen dos gêneros Cyphomandra, Dyssochroma, Nicotiana, Physalis e Sessea (Solanaceae). Figura 28. Cyphomandra velutina Sendtn., vista equatorial evidenciando o cólporo. Figuras 29-31. Dyssochroma viridiflora (Sims) Ducke. 29. Vista polar. 30. Vista equatorial evidenciando o cólporo. 31. L.O. em dois níveis de focalização. Figuras 32-34. Nicotiana langsdorffii (Weinm.) Roem. \& Schult. 32. Vista polar. 33. Vista equatorial evidenciando o cólporo. 34. L.O. em dois níveis de focalização. Figuras 35-37. Physalis peruviana L. 35. Vista polar. 36. Vista equatorial evidenciando o cólporo. 37. Vista equatorial evidenciando a sobreposição das endoaberturas. Figuras 38-39. Physalis viscosa L. 38. Vista polar. 39. Vista equatorial evidenciando o cólporo. Figuras 40-41. Sessea brasiliensis Tol. 40. Vista polar. 41. Vista equatorial evidenciando o cólporo. Barras da escala $=5 \mu \mathrm{m}(31,34)$; $10 \mu \mathrm{m}(28-30,32-33,35-41)$.

Figures 28-41. Photomicrographs of pollen grains of genera Cyphomandra, Dyssochroma, Nicotiana, Physalis e Sessea (Solanaceae). Figure 28. Cyphomandra velutina Sendtn., equatorial view showing aperture. Figures 29-31. Dyssochroma viridiflora (Sims) Ducke. 29. Polar view. 30. Equatorial view showing aperture. 31. L.O. in high and low focus. Figures 32-34. Nicotiana langsdorffi (Weinm.) Roem. \& Schult. 32. Polar view. 33. Equatorial view showing aperture. 34. L.O. in ligh and low focus. Figures 35-37. Physalis peruviana L. 35. Polar view. 36. Equatorial view showing aperture. 37. Equatorial view showing the overlap of endoapertures. Figures 38-39. Physalis viscosa L. 38. Polar view. 39. Equatorial view showing aperture. Figures 40-41. Sessea brasiliensis Tol. 40. Polar view. 41. Equatorial view showing aperture. $\operatorname{Bar}=5 \mu \mathrm{m}(31,34) ; 10 \mu \mathrm{m}(28-30,32-33,35-41)$. 
A.M. Ladeira s.n., SP159206: $\mathrm{P}=22,0 ; \mathrm{E}=18,4 ;$ diâm. equatorial em vista polar $=18,0$.

T. Sendulsky 495: $\mathrm{P}=20,9 ; \mathrm{E}=21,4$; diâm. equatorial em vista polar $=20,2$.

Observações: Os materias da Reserva F.C. Hoehne s.n. (SP31794) e T. Sendulsky 472 (SP), citados por Carvalho (1985), não foram estudados por possuírem somente frutos ou por falta de material polínico. Wiebke \& Wiebke (1974) definiram a ornamentacão de Solanum americanum como subreticulada, ao passo que nos espécimes aqui analisados ela foi definida como escabrada. Os referidos autores descreveram os grãos dessa espécie como tendo o diâmetro equatorial em vista polar $=21,8(18,9-25,2 \mu \mathrm{m})$. Os valores dos espécimes aqui medidos encontram-se dentro da faixa de variação do material citado por esses autores. Batista-Franklim \& Gonçalves-Esteves (2008), ao estudarem palinologicamente as espécies de Solanum ocorrentes na restinga do Estado do Rio de Janeiro, analisaram os grãos de pólen de $S$. americanum var. americanum, e observaram resultados semelhantes aos aqui apresentados para a espécie quanto ao tamanho, à forma, a ornamentação da sexina e às aberturas. No entanto, as autoras ressaltaram que a sexina da variedade analisada apresentava-se granulada quando observada em microscopia eletrônica de varredura.

Material estudado: 21-II-1976, G. Davidse \& W.G. D'Arcy 10487 (SP); 11-IV-1979, M. Kirizawa 414 (SP); 12-III-1957, M. Kuhlmann s.n. (SP154574); 7-XII-1978, A.M. Ladeira s.n. (SP159206); 7-XII-1966, T. Sendulky 495 (SP).

\section{Solanum atropurpureum Schrank.}

\section{Figuras 48-50}

Forma: prolato-esferoidal, âmbito subtriangular.

Aberturas: 3 cólporos, colpos longos, com margem; endoaberturas lalongadas, com extremidades afiladas, providas de fastígio não conspícuo.

Exina: microrreticulada.

Medidas $(\mu \mathrm{m})$ : S.L. Jung et al. 302: $\mathrm{P}=31,7 \pm 0,3 ; \mathrm{E}=30,3 \pm 0,3$; diâm. equatorial em vista polar $=29,8 \pm 0,3$; apocolpo ca. 8,4 ; cólporo compr. ca. 23,4, larg. ca. 3,9; endoabertura compr. ca. 7,6, larg. ca. 18,4; exina ca. 2,6, sexina ca. 2,0, teto ca. 0,6 e nexina ca. 0,6 .

G. Davidse \& W.G. D'Arcy 10430: $\mathrm{P}=33,6$; $\mathrm{E}=31,1$; diâm. equatorial em vista polar $=29,7$.

Observações: Os materias B. Skvortzov s.n.
(SP106043) e T. Sendulsky 583 (SP), citados por Carvalho (1985), não foram estudados por possuírem apenas frutos ou por escassez de material polínico.

Material estudado: 21-II-1976, G. Davidse \& W.G. D'Arcy 10430 (SP); 11 -XI-1980, S.L. Jung et al. 302 (SP).

\section{Solanum bullatum Vell.}

Figuras 51-52

Forma: oblato-esferoidal a prolato-esferoidal, âmbito subtriangular.

Aberturas: 3 cólporos, colpos longos, com margem; endoaberturas lalongadas, com leve constrição mediana, com extremidades arredondadas, providas de fastígio não conspícuo.

Exina: psilada.

Medidas ( $\mu \mathrm{m})$ : M.S.F. Silvestre 43: $\mathrm{P}=19,8 \pm 0,2$; $\mathrm{E}=19,5 \pm 0,1$; diâm. equatorial em vista polar $=18,7 \pm 0,2$; apocolpo ca. 3,7; cólporo compr. ca. 15,2 , larg. ca. 2,4 , margem ca. 0,9 ; endoabertura compr. ca. 5,1, larg. ca. 9,5; exina ca. 1,6, sexina ca. 1,2 , teto ca. 0,5 e nexina ca. 0,4 .

F. Barros 535: $\mathrm{P}=19,6 ; \mathrm{E}=20,9$; diâm. equatorial em vista polar $=19,8$.

G. Davidse \& W.G. D'Arcy 10503: $\mathrm{P}=19,8$; $\mathrm{E}=20,1$; diâm. equatorial em vista polar $=19,0$.

S.L. Jung et al. $387: \mathrm{P}=19,6 ; \mathrm{E}=19,6$; diâm. equatorial em vista polar $=18,8$.

J.C. Gomes Jr. s.n., SP81378: P = 19,9; E =20,9; diâm. equatorial em vista polar $=19,5$.

R.A. Pinho 35: $\mathrm{P}=18,5 ; \mathrm{E}=18,8$; diâm. equatorial em vista polar $=18,5$.

Observações: O material da Reserva W. Hoehne 6-203 (SP), citado por Carvalho (1985), não foi estudado por escassez de material polínico. Os dados aqui obtidos corroboram o estudo de Barth \& Duarte (2008) para os grãos de pólen da espécie, no entanto, os diâmetros dos grãos de pólen estudados pelas referidas autoras são relativamente maiores que os aqui observados ( $\mathrm{P}=28,8 \mu \mathrm{m}$ (27-33) e $\mathrm{E}=26,6 \mu \mathrm{m}(24-29)$.

Material estudado: 14-X-1980, F. Barros 535 (SP); 21-II-1976, G. Davise \& W.G. D'Arcy 10503 (SP); 25-II-1965, J.C. Gomes Jr. s.n. (SP81378); 10-VI-1981, S.L. Jung et al. 387 (SP); 13-I-1964, R.A. Pinho 35 (SP); 12-V-1977, M.S.F. Silvestre 43 (SP).

\section{Solanum capsicoides Allion.}

Figuras 53-54 
Forma: oblato-esferoidal, âmbito subtriangular.

Aberturas: 3 cólporos, colpos longos, com margem; endoaberturas lalongadas, com constrição mediana, com extremidades arredondadas, providas de fastígio conspícuo.

Exina: rugulada na região do mesocólporo e com rúgulas esparsas na região polar.

Medidas $(\mu \mathrm{m}): \mathrm{P}=26,0 \pm 0,2 ; \mathrm{E}=26,3 \pm 0,3 ;$ diâm. equatorial em vista polar $=24,4 \pm 0,2$; apocolpo ca. 4,7; cólporo compr. ca. 18,4, larg. ca. 2,3; endoabertura compr. ca. 3,9, larg. ca. 13,3; exina ca. 1,9 , exina ca. 1,4 , teto ca. 0,6 e nexina ca. 0,5 .

Observações: O material da Reserva T. Sendulsky 623A (SP), citado por Carvalho (1985), não foi estudado por escassez de material polínico. Ao estudarem os grãos de pólen de $S$. capsicoides, Batista-Franklim \& Gonçalves-Esteves (2008) descreveram-os como sendo prolato-esferoidais, endoaberturas com extremidades agudas cruzando no mesocolpo parecendo um endocingulo, desprovidas de constrição mediana e com ornamentação da sexina granulada com grânulos conspícuos, dados que diferem dos observados no espécime analisado no presente estudo.

Material estudado: 2-XII-1966, T. Sendulsky 526 (SP).

\section{Solanum cernuum Vell.}

Figuras 55-56

Forma: prolato-esferoidal, âmbito circular.

Abertura: 3 cólporos, colpos longos, com margem; endoaberturas lalongadas, com extremidades truncadas, providas de fastígio não conspícuo.

Exina: escabrada.

Medidas $(\mu \mathrm{m}): \mathrm{P}=26,9 \pm 0,1 ; \mathrm{E}=26,0 \pm 0,1 ;$ diâm. equatorial em vista polar $=25,9 \pm 0,1$; apocolpo ca. 3,7; cólporo compr. ca. 19,9, larg. ca. 3,0; endoabertura compr. ca. 5,8, larg. ca. 9,7; exina ca. 1,6, sexina ca. 1,2, teto ca. 0,5 e nexina ca. 0,4.

Observações: Os materias A. Custodio Filho et al. 69 (SP), G. Davidse \& W.G. D'Arcy 10514 (SP), I.C.C. Macedo 13 (SP), W. Mantovani 42 (SP) e M. Sakane 485 (SP), citados por Carvalho (1985), não foram estudados por possuírem somente frutos ou por escassez de material polínico. Posteriormente outro material da Reserva, A.M. Fortes \& S. Romaniuc Neto 19 (SP); foi identificado como S. cernuum e incluído no presente estudo.

Material estudado: 8-VI-1982, A.M. Fortes \& S. Romaniuc Neto 19 (SP).

\section{Solanum concinnum Schott ex Sendtn.}

Figuras 57-59

Forma: oblato-esferoidal, prolato-esferoidal a subprolata, âmbito sutriangular.

Abertura: 3 cólporos, colpos longos, com margem; endoaberturas lalongadas, com constrição mediana, com extremidades arredondadas, providas de fastígio conspícuo.

Exina: microrreticulada.

Medidas $(\mu \mathrm{m})$ : A. Custodio Filho 7: $\mathrm{P}=24,1 \pm 1,0 ; \mathrm{E}=24,1 \pm 0,2$; diâm. equatorial em vista polar $=22,7 \pm 0,2$; apocolpo ca. 3,1 ; cólporo compr. ca. 19,6, larg. ca. 4,0; endoabertura compr. ca. 4,0, larg. ca. 10,9; exina ca. 1,9; sexina ca. 1,2, teto ca. 0,4 e nexina ca. 0,4 .

F. Barros 531: $\mathrm{P}=23,7 ; \mathrm{E}=20,5$; diâm. equatorial em vista polar $=22,7$.

F.S. Cavalcante et al. 3: $\mathrm{P}=22,2 ; \mathrm{E}=23,8$; diâm. equatorial em vista polar $=21,8$.

J.A. Corrêa 66: $\mathrm{P}=26,1 ; \mathrm{E}=26,3$; diâm. equatorial em vista polar $=23,3$.

J.A. Corrêa 85: $\mathrm{P}=24,6 ; \mathrm{E}=23,8$; diâm. equatorial em vista polar $=23,5$.

S.A. Corrêa et al. 5: $\mathrm{P}=21,8 ; \mathrm{E}=22,5$; diâm. equatorial em vista polar $=23,2$.

A. Custodio Filho 121: $\mathrm{P}=17,9 ; \mathrm{E}=15,3$; diâm. equatorial em vista polar $=22,2$.

F. Oliveira 11: $\mathrm{P}=25,0 ; \mathrm{E}=24,1 ;$ diâm. equatorial em vista polar $=21,5$.

M. Sakane 127: $\mathrm{P}=20,7 ; \mathrm{E}=20,1$; diâm. equatorial em vista polar $=18,1$.

T. Sendulsky 759: $\mathrm{P}=22,2 ; \mathrm{E}=20,6$; diâm. equatorial em vista polar $=19,9$.

T. Sendulsky 835: $\mathrm{P}=25,4 ; \mathrm{E}=23,5$; diâm. equatorial em vista polar $=24,3$.

T. Sendulsky 977: $\mathrm{P}=26,2 ; \mathrm{E}=25,8$; diâm. equatorial vista polar $=24,7$.

B.C. Teixeira 269: $\mathrm{P}=23,0 ; \mathrm{E}=24,0$; diâm. equatorial em vista polar $=25,7$.

Observações: Os materiais da Reserva F.C. Hoehne s.n. (SP28119) e J. Mattos 12638 (SP), citados por Carvalho (1985), não foram estudados por falta de material polínico.

Material estudado: 14-X-1980, F. Barros 531 (SP); 23-XI-1976, F.S. Cavalcante et al. 3 (SP); 28-V-1974, J.A. Corrêa 66 (SP); 23-VII-1974, J.A. Corrêa 85 (SP); 31-I-1979, S.A. Corrêa et al. 5 (SP); 1-II-1979, A. Custodio Filho 7, (SP), 8-VIII-1979, A. Custodio Filho 121 (SP); 13-X-1970, F. Oliveira 11 (SP18946); 19-VII-1974, M. Sakane 127 (SP); 

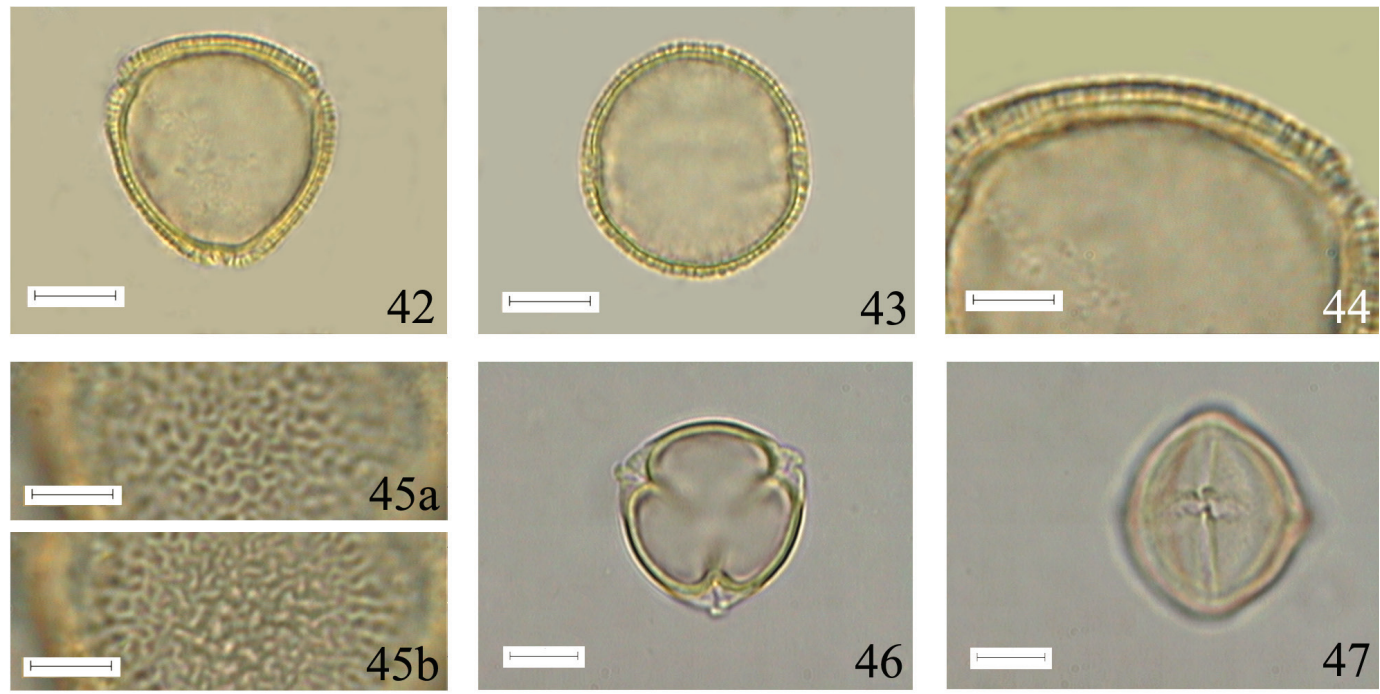

46
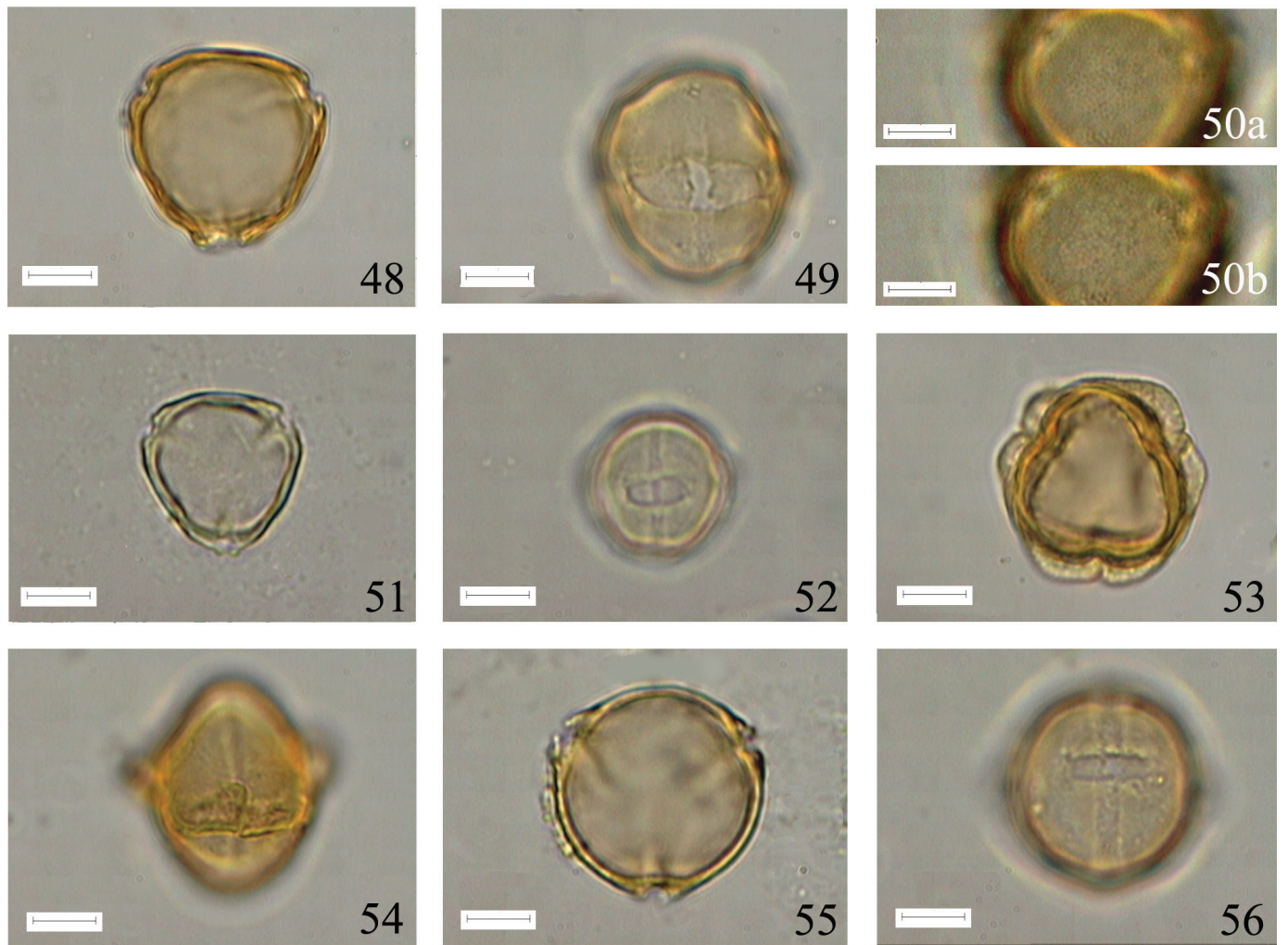

Figuras 42-56. Fotomicrografias dos grãos de pólen dos gêneros Solandra e Solanum (Solanaceae). Figuras 42-45. Solandra grandiflora Sw. 42. Vista polar. 43. Vista equatorial em corte óptico. 44. Detalhe da exina em corte óptico. 45. L.O. em dois níveis de focalização. Figuras 46-47. Solanum americanum Mill. 46. Vista polar. 47. Vista equatorial evidenciando o cólporo. Figuras 48-50. Solanum atropurpureum Schrank. 48. Vista polar. 49. Vista equatorial evidenciando o cólporo. 50. L.O. em dois níveis de focalização. Figuras 51-52. Solanum bullatum Vell. 51. Vista polar. 52. Vista equatorial evidenciando o cólporo. Figuras 53-54. Solanum capsicoides Allion. 53. Vista polar. 54. Vista equatorial evidenciando o cólporo. Figuras 55-56. Solanum cernuum Vell. 55. Vista polar. 56. Vista equatorial evidenciando o cólporo. Barras da escala $=5 \mu \mathrm{m}(44-45,50) ; 10 \mu \mathrm{m}(42-43,46-49,51-56)$.

Figures 42-56. Photomicrographs of pollen grains of genera Solandra e Solanum (Solanaceae). Figures 42-45. Solandra grandiflora Sw. 42. Polar view. 43. Equatorial view in optical section. 44. Exine in optical section. 45. L.O. in ligh and low focus. Figures 46-47. Solanum americanum Mill. 46. Polar view. 47. Equatorial view showing aperture. Figures 48-50. Solanum atropurpureum Schrank. 48. Polar view. 49. Equatorial view showing aperture. 50. L.O. in high and low focus. Figures 51-52. Solanum bullatum Vell. 51. Polar view. 52. Equatorial view showing aperture. Figures 53-54. Solanum capsicoides Allion. 53. Polar view. 54. Equatorial view showing aperture. Figures 55-56. Solanum cernuum Vell. 55. Polar view. 56. Equatorial view showing aperture. Bar $=5 \mu \mathrm{m}$ (figures $44-45$, 50); $10 \mu \mathrm{m}$ (42-43, 46-49, 51-56). 
10-VIII-1967, T. Sendulsky 835 (SP); 1-VII-1968, T. Sendulsky 759 (SP); 10-VII-1968, T. Sendulsky 977 (SP); 7-VII-1965, B.C. Teixeira 269 (SP).

\section{Solanum didymum Dun.}

Figuras 60-62

Forma: prolato-esferoidal, âmbito subtriangular.

Abertura: 3 cólporos, colpos longos, com constrição mediana, com margem; endoaberturas lalongadas, com extremidades afilada; providas de fastígio conspícuo.

Exina: microrreticulada.

Medidas $(\mu \mathrm{m}): \mathrm{P}=22,2 \pm 0,2 ; \mathrm{E}=21,4 \pm 0,3 ;$ diâm equatorial em vista polar $=19,4 \pm 0,2$; apocolpo ca. 3,1; cólporo compr. ca. 18,5 , larg ca. 3,3; endoabertura compr. ca. 3,3, larg. ca. 9,2; exina ca. 1,7, sexina ca. 0,9 , teto ca. 0,6 e nexina ca. 0,6.

Material estudado: 21-VII-1931, W. Hoehne s.n. (SP28146).

\section{Solamum diflorum Vell.}

Figuras 63-65

Forma: prolato-esferoidal, âmbito subtriangular.

Abertura: 3 cólporos, colpos longos, com margem; endoaberturas lalongadas, com constrição mediana, com extremidades truncadas, providas de fastígio não conspícuo.

Exina: microrreticulada.

Medidas $(\mu \mathrm{m}): \mathrm{P}=20,1 \pm 0,4 ; \mathrm{E}=19,1 \pm 0,4 ;$ diâm. equatorial em vista polar $=19,9 \pm 0,3$; apocolpo ca. 3,9; cólporo compr. ca. 15,6, larg. ca. 2,8; endoabertura compr. ca. 4,8, larg. ca. 10,2; exina ca. 1,5 , sexina ca. 1,0 , teto ca. 0,4 e nexina ca. 0,4 .

Observações: O material da Reserva F.C. Hoehne 4030 (SP), citado por Carvalho (1985), não foi estudado por falta de material polínico.

Material estudado: 6-VIII-1968, T. Sendulsky $958(\mathrm{SP})$.

9. Solanum excelsum St. Hil. ex Dun.

Figuras 66-67

Forma: oblato-esferoidal a prolato-esferoidal, âmbito subtriangular.

Aberturas: 3 cólporos, colpos longos, com margem; endoaberturas lalongadas, com extremidades truncadas, providas de fastígio conspícuo.

Exina: rugulada.

Medidas ( $\mu \mathrm{m})$ : O. Handro s.n., SP29413: $\mathrm{P}=21,9 \pm 0,2 ; \mathrm{E}=21,5 \pm 0,4$ diâm. equatorial em vista polar $=21,5 \pm 0,5$; apocolpo ca. 2,0; cólporo compr. ca. 17,8 , larg. ca. 4,9; endoabertura compr. 4,2, larg. ca. 10,2 ; exina ca. 1,9 , sexina ca. 1,6 , teto ca. 0,7 e nexina ca. 0,6 .

F. Barros 536: $\mathrm{P}=22,7 ; \mathrm{E}=20,4$; diâm. equatorial em vista polar $=18,9$.

M. Kuhlmann 3430: $\mathrm{P}=23,2 ; \mathrm{E}=22,6$; diâm. equatorial em vista polar $=21,1$.

M.S.F. Silvestre 209; $\mathrm{P}=20,1 ; \mathrm{E}=20,7$; diâm. equatorial em vista polar $=19,3$.

Material estudado: 17-X-1980, F. Barros 536 (SP); 31-III-1932, O. Handro s.n. (SP29413); 20-X-1948, M. Kuhlmann 3430 (SP); 26-IX-1979, M.S.F. Silvestre 209 (SP).

\section{Solanum granuloso-leprosum Dun.}

Figuras 68-70

Forma: oblato-esferoidal, âmbito subtriangular.

Aberturas: 3(-4) cólporos, colpos longos, com constrição mediana, com margem; endoaberturas lalongadas, com extremidades arredondadas, providas de fastígio.

Exina: microrreticulada

Medidas $(\mu \mathrm{m}): \mathrm{P}=21,2 \pm 0,3 ; \mathrm{E}=21,7 \pm 0,3$; diâm. equatorial em vista polar $=20,3 \pm 0,2$; apocolpo ca. 3,5; cólporo compr. ca. 16,7, larg. ca. 3,3; endoabertura compr. ca. 3,4, larg. ca. 9,2; exina ca. 1,9, sexina ca. 1,2 , teto ca. 0,5 e nexina ca. 0,5 .

Observações: No espécime de herbário aqui estudado, constatou-se a presença de grãos de pólen com 4 aberturas $(8 \%)$.

Material estudado: s.d., M. Sakane 126 (SP).

\section{Solanum hoehnei Morton}

Figuras 71-72

Forma: prolato-esferoidal a subprolata, âmbito subtriangular.

Aberturas: 3 cólporos, colpos curtos; endoaberturas lalongadas, formando um anel contínuo ao redor do grão de pólen (endocingulo), providas de fastígio conspícuo.

Exina: escabrada.

Medidas $(\mu \mathrm{m})$ : M. Kirizawa 159: $\mathrm{P}=28,2 \pm 0,7$; $\mathrm{E}=21,6 \pm 0,4$; diâm. equatorial em vista polar $=21,4 \pm 0,4$; apocolpo ca. 4,5 ; cólporo compr. ca. 20,0, larg. ca. 2,2; endoabertura compr. ca. 5,4, larg. ca. 11,1 ; exina ca. 2,4 , sexina ca. 1,5 , teto ca. 0,9 e nexina ca. 0,9 .

S.L. Jung 270: $\mathrm{P}=23,9 ; \mathrm{E}=20,6$; diâm. equatorial em vista polar $=21,3$. 

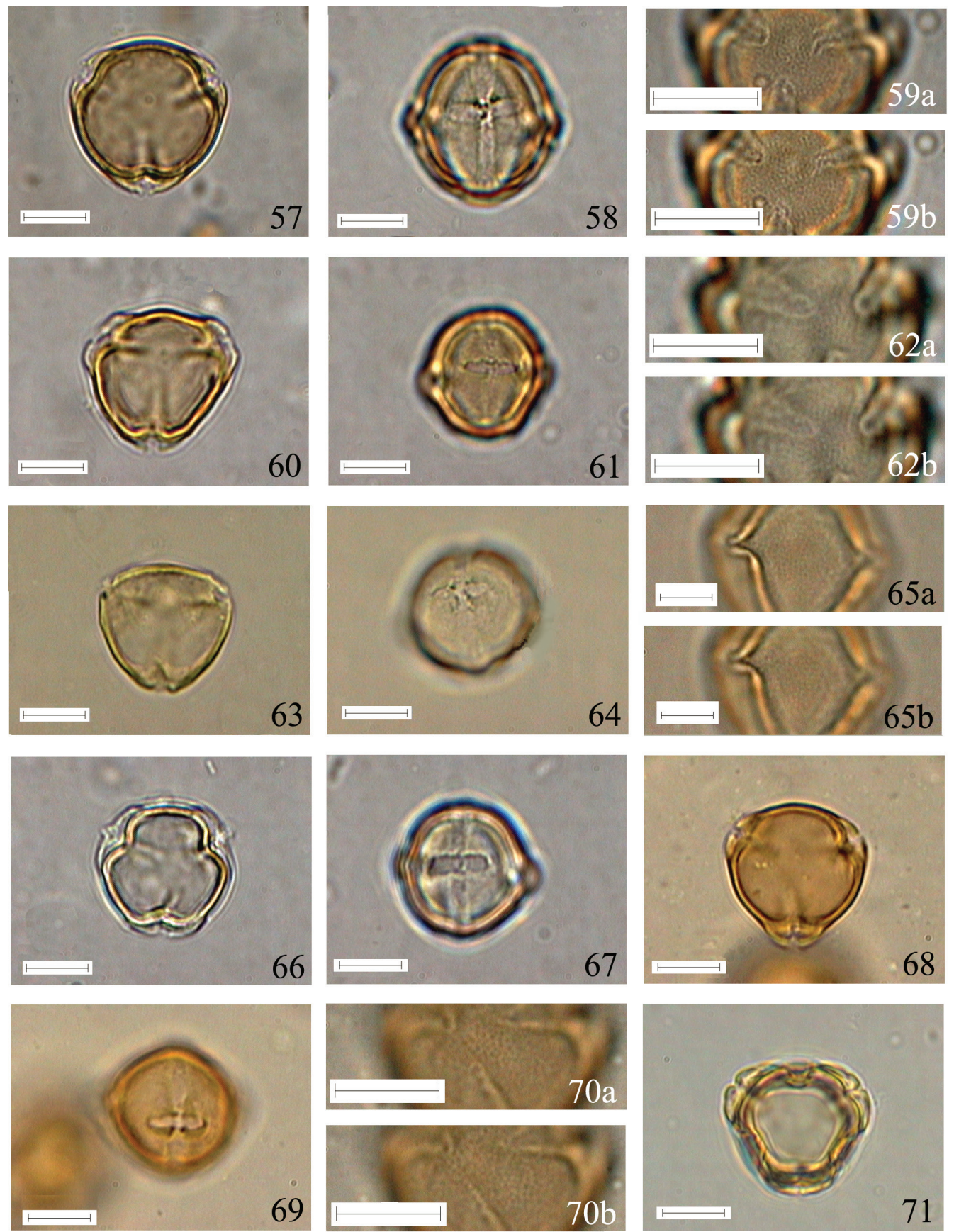

Figuras 57-71. Fotomicrografias dos grãos de pólen do gênero Solanum (Solanaceae). Figuras 57-59. Solanum concinnum Schott ex Sendtn. 57. Vista polar. 58. Vista equatorial evidenciando o cólporo. 59. L.O. em dois níveis de focalização. Figuras 60-62. Solanum didynum Dun. 60. Vista polar. 61. Vista equatorial evidenciando o cólporo. 62. L.O. em dois níveis de focalização. Figuras 63-65. Solanum diflorum Vell. 63. Vista polar. 64. Vista equatorial evidenciando o cólporo. 65. L.O. em dois níveis de focalização. Figuras 66-67. Solanum excelsum St. Hil. ex Dun. 66. Vista polar. 67. Vista equatorial evidenciando o cólporo. Figuras 68-70. Solanum granuloso-leprosum Dunal. 68. Vista polar. 69. Vista equatorial evidenciando o cólporo. 70. L.O. em dois níveis de focalização. Figura 71. Solanum hoehnei Morton., vista polar. Barras de escala $=5 \mu \mathrm{m}(59,62,65,70) ; 10 \mu \mathrm{m}(57-58,60-61,63-64,66-69,71)$.

Figures 57-71. Photomicrographs of pollen grains of genus Solanum (Solanaceae). Figures 57-59. Solanum concinnum Schott ex Sendtn. 57. Polar view. 58. Equatorial view showing aperture. 59. L.O. in high and low focus. Figures 60-62. Solanum didynum Dun. 60. Polar view. 61. Equatorial view showing aperture. 62. L.O. in high and low focus. Figures 63-65. Solanum diflorum Vell. 63. Polar view. 64. Equatorial view showing aperture. 65. L.O. in high and low focus. Figures 66-67. Solanum excelsum St. Hil. ex Dun. 66. Polar view. 67. Equatorial view showing aperture. Figures 68-70. Solanum granuloso-leprosum Dunal. 68. Polar view. 69. Equatorial view showing aperture. 70. L.O. in high and low focus. Figure 71. Solanum hoehnei Morton., polar view. Bar $=5 \mu \mathrm{m}(59,62,65,70) ; 10 \mu \mathrm{m}(57-58,60-$ 61, 63-64, 66-69, 71). 
M. Kirizawa 535: $\mathrm{P}=24,6 ; \mathrm{E}=22,0$; diâm. equatorial em vista polar $=21,4$.

M. Kuhlmann 3422: $\mathrm{P}=27,5 ; \mathrm{E}=22,4$; diâm. equatorial em vista polar $=21,3$.

H. Makino 151: $\mathrm{P}=21,9 ; \mathrm{E}=19,9$; diâm. equatorial em vista polar $=19,6$.

H. Makino et al. 148: $\mathrm{P}=22,9 ; \mathrm{E}=20,1$; diâm. equatorial em vista polar $=18,0$.

Observações: O material da Reserva C.G. Fonseca 36 (SP), citado por Carvalho (1985), não foi estudado por possuir apenas frutos.

Material estudado: 5-X-1978, S.L. Jung 270 (SP); 19-XII-1977, M. Kirizawa 159 (SP); 12-III-1980, M. Kirizawa 535 (SP); 4-XI-1947, M. Kuhlmann 3422 (SP); 19-IV-1979, H. Makino 151 (SP); 18-VII-1978, H. Makino et al. 148 (SP).

\section{Solanum inaequale Vell.}

Figuras 73-74

Forma: prolato-esferoidal, âmbito subtriangular.

Aberturas: 3 cólporos, colpos longos; endoaberturas lalongadas, com extremidades arredondadas, com margem, providas de fastígio.

Exina: escabrada.

Medidas ( $\mu \mathrm{m})$ : F.C. Hoehne s.n., SP28274: $\mathrm{P}=20,1 \pm 0,2 ; \mathrm{E}=19,2 \pm 0,2 ;$ diâm. equatorial em vista polar $=19,5 \pm 0,2 ;$ apocolpo; 5,4 cólporo compr. ca. 17,0 , larg. ca. 3,1 ; endoabertura compr. ca. 4,2, larg. ca. 11,5; exina ca. 3,0 , sexina ca. 2,2 , teto ca. 1,1 e nexina ca. 0,9 .

A. Hodgson 10: $\mathrm{P}=185 ; \mathrm{E}=17,4$; diâm. equatorial em vista polar $=18,7$.

Observações: Batista-Franklin \& Gonçalves-Esteves (2008) citaram que os espécimes de $S$. inaequale apresentaram grãos de pólen com forma oblato-esferoidal e prolato-esferoidal. No presente estudo os espécimes da espécie apresentaram apenas grãos de pólen prolato-esferoidais

Material estudado: 23-XI-1931, F.C. Hoehne s.n. (SP28274); 15-IX-1960, A. Hodgson 10 (SP).

\section{Solanum inodorum Vell.}

Figuras 75-76

Forma: oblato-esferoidal a prolato-esferoidal, âmbito subtriangular.

Aberturas: 3 cólporos, colpos longos; endoaberturas lalongadas, com extremidades truncadas, presença de fastígio.

Exina: microrreticulada.

Medidas $(\mu \mathrm{m})$ : F.C. Hoehne s.n., SP29800:
$\mathrm{P}=21,8 \pm 0,3 ; \mathrm{E}=23,0 \pm 0,4$; diâm. equatorial em vista polar $=22,2 \pm 0,2$; apocolpo 3,8; cólporo compr. ca. 17,8, larg. ca. 6,0 ; endoabertura compr. ca. 4,5, larg. ca. 10,7 ; exina ca. 2,7 , sexina ca. 1,8 , teto ca. 0,8 e nexina ca. 0,9 .

S.L. Jung 11: $\mathrm{P}=19,2 ; \mathrm{E}=21,4$; diâm. equatorial em vista polar $=20,8$.

S.L. Jung et al. 261: $\mathrm{P}=19,4 ; \mathrm{E}=19,4$; diâm. equatorial em vista polar $=20,5$.

H. Makino 135: $\mathrm{P}=21,5 ; \mathrm{E}=21,5$; diâm. equatorial em vista polar $=22,9$.

M. Sakane 128: $\mathrm{P}=20,0 ; \mathrm{E}=19,7$; diâm. equatorial em vista polar $=19,3$.

M.S.F. Silvestre 213: $\mathrm{P}=21,3 ; \mathrm{E}=23,5$; diâm. equatorial em vista polar $=24,0$.

Observações: Os materiais da Reserva T.M. Cerati et al. 2 (SP), S.L. Jung 12 (SP), S.L. Jung 267 (SP), M. Kirizawa 181 (SP), H. Makino 142 (SP), M.M.R.F. Melo 6 (SP), T. Sendulsky 998 (SP), T. Sendulsky 999 (SP), citados por Carvalho (1985), não foram estudados por falta de material polínico ou por possuírem apenas frutos.

Material estudado: 26-X-1931, F.C. Hoehne s.n. (SP29800); 2-V-1977, S.L. Jung 11, (SP); 4-VII-1978, S.L. Jung et al. 261 (SP); 18-VII-1978, H. Makino 135 (SP); 23-VII-1974, M. Sakane 128(SP); 26-XI-1979, M.S.F. Silvestre 213 (SP).

\section{Solanum lycocarpum St. Hil ex Dun.}

Figuras 77-78

Forma: oblato-esferoidal, âmbito subtriangular ou eliptico.

Aberturas: 2-3 cólporos, colpos longos, com margem; endoaberturas lalongadas, com constrição mediana, extremidades arredondadas, com margem, providas de fastígio conspícuo.

Exina: rugulada.

Medidas $(\mu \mathrm{m})$ : 3 -aberturas: $\mathrm{P}=31,4 \pm 0,3$; $\mathrm{E}=33,2 \pm 0,4$; diâm. equatorial em vista polar $=34,2 \pm 0,3$; cólporo larg. ca. 4,2; endoabertura compr. ca. 9,7, larg. ca. 19,9, margem ca. 1,4; exina ca. 1,8 , sexina ca. 1,2 , teto ca. 0,6 e nexina ca. 0,6 . 2-aberturas: $\mathrm{E}_{\mathrm{M}}=34,9 \pm 0,2 ; \mathrm{E}_{\mathrm{m}}=30,8 \pm 0,3$; exina ca. 1,8 , sexina ca. 1,2 , teto ca. 0,5 e nexina ca. 0,7 .

Observações: O material aqui estudado apresentou ocasionalmente grãos de pólen com cólporos muito longos que se unem nos pólos, parecendo sincolpados por causa do rompimento da área polar muito reduzida. Para o espécime de herbário aqui estudado constatou-se a presença de $54 \%$ de grãos de pólen 3 -colporados e $46 \%$ de grãos de pólen 2 -colporados. 
Salgado-Labouriau et al. (1969) descreveram os grãos de pólen de S. lycocarpum como 3-colporados, psilados, com diâmetros de $\mathrm{P}=25,1 \mu \mathrm{m}$ (22-31) e $\mathrm{E}=28,1 \mu \mathrm{m}$ (25-30), ao passo que o espécime aqui analisado apresenta grãos de pólen 2-3 colporados, rugulados e com diâmetros maiores.

Material estudado: 2-XII-1966, T. Sendulsky 467 (SP).

\section{Solanum mauritianum Scop.}

Figuras 79-80

Forma: oblato-esferoidal a prolato-esferoidal, âmbito subcircular.

Aberturas: 3 cólporos, colpos longos, com constrição mediana, com margem; endoaberturas lalongadas, com constrição mediana, extremidades afiladas, com margem, presença de fastígio não conspícuo.

Exina: microrreticulada.

Medidas $(\mu \mathrm{m}):$ J.A. Corrêa 155: $\mathrm{P}=28,0 \pm 0,3$; $\mathrm{E}=27,5 \pm 0,1$; diâm. equatorial em vista polar $=27,6 \pm 0,2$; apocolpo ca. 6,4; cólporo larg. ca. 4,2, margem ca. 1,4; endoabertura compr. ca. 5,3, larg. ca. 13,6, margem ca. 1,7; exina ca. 1,6, sexina ca. 1,0 , teto ca. 0,5 e nexina ca. 0,7 .

F. Barros 530: $\mathrm{P}=28,0 ; \mathrm{E}=28,7$; diâm. equatorial em vista polar $=28,7$;

S.A. Correa et al. 17: $\mathrm{P}=28,9 ; \mathrm{E}=29.8$; diâm. equatorial em vista polar $=28,0$.

Observações: Os materiais da Reserva A. Custodio Filho 122 (SP) e G. Davidse \& W.G. D'Arcy 10484 (SP), citados por Carvalho (1985), apresentaram grãos de pólen amassados. Batista-Franklim \& Gonçalves-Esteves (2008) descreveram para a espécie grãos de pólen esferoidais, com endoaberturas de extremidades truncadas e ornamentação granulada, características que diferem das encontradas nos três espécimes aqui analisados.

Material estudado: 14-X-1980, F. Barros 530 (SP); 6-VIII-1976, J.A. Corrêa 155 (SP); 27-VII-1979, S.A. Correa et al. 17 (SP).

\section{Solanum paniculatum $\mathrm{L}$.}

Figuras 81-82

Forma: oblato-esferoidal a prolato-esferoidal, âmbito circular.

Aberturas: 3 cólporos, colpos longos, com margem; endoaberturas lalongadas, extremidades afiladas, com margem, providas de fastígio não conspícuo.
Exina: microrreticulada.

Medidas $(\mu \mathrm{m})$ : Souza 1: $\mathrm{P}=32,2 \pm 0,2$; $\mathrm{E}=33,1 \pm 0,3$; diâm. equatorial em vista polar $=33,1 \pm 0,4$; apocolpo ca. 5,2; cólporo larg. ca. 4,2, margem ca. 1,1 ; endoabertura compr. ca. 6,6, larg. ca. 18,3, margem ca. 1,2 ; exina ca. 1,9 , sexina ca. 1,3 , teto ca. 0,6 e nexina ca. 0,7 .

J.C. Camargo 61: $\mathrm{P}=31,2 ; \mathrm{E}=29,7$; diâm. equatorial em vista polar $=29,2$.

T. Sendulsky 459: $\mathrm{P}=31,6 ; \mathrm{E}=35,3$; diâm. equatorial em vista polar $=31,3$.

Observações: Os materiais da Reserva F. Oliveira 18 (SP) e L. Rodrigues 2 (SP); citados por Carvalho (1985); apresentaram grãos de pólen amassados. Para Batista-Franklim \& Gonçalves-Esteves (2008), os grãos de pólen de S. paniculatum são prolato-esferoidais, com endoaberturas de extremidades arredondadas e granulados, diferindo desta forma, dos dados encontrados para os grãos de pólen da espécie neste estudo.

Material estudado: 1-VIII-1966, J.C. Camargo 61 (SP); 2-XII-1966, T. Sendulsky 459 (SP); 15-XI-1967, Souza 1 (SP).

\section{Solanum rufescens Sendtn.}

Figuras 83-84

Forma: oblato-esferoidal a prolato-esferoidal, âmbito subtriangular.

Aberturas: 3(-4) cólporos, colpos longos, com margem; endoaberturas lalongadas, com constrição mediana, extremidades afiladas, com margem, presença de fastígio não conspícuo.

Exina: microrreticulada.

Medidas $(\mu \mathrm{m})$ : H. Makino et al. 147: $\mathrm{P}=27,8 \pm 0,2 ; \mathrm{E}=25,1 \pm 0,2 ;$ diâm. equatorial em vista polar $=26,0 \pm 0,5$; apocolpo ca. 5,2; cólporo larg. ca. 3,9, margem ca. 0,9 ; endoabertura compr. ca. 6,7 , larg. ca. 13,7, margem ca. 1,2 ; exina ca. 1,7 , sexina ca. 1,1 , teto ca. 0,5 e nexina ca. 0,6 .

A. Custodio Filho 125: $\mathrm{P}=24,0 ; \mathrm{E}=25,6$; diâm. equatorial em vista polar $=22,8$.

T. Sendulsky 1037: $\mathrm{P}=23,4 ; \mathrm{E}=24,5$; diâm. equatorial em vista polar $=23,4$;

Observações: Os materiais da Reserva F. Barros 529 (SP), S.A. Corrêa et al. 16 (SP), A. Custodio Filho et al. 24 (SP), T.P. Guerra 2 (SP), F.C. Hoehne s.n. (SP28142), M. Kuhlmann 3432 (SP), H. Makino et al. 31 (SP), W. Mantovani 21 (SP), J. Mattos 12639 (SP), F. Oliveira 16 (SP), R.A. Pinho 37 

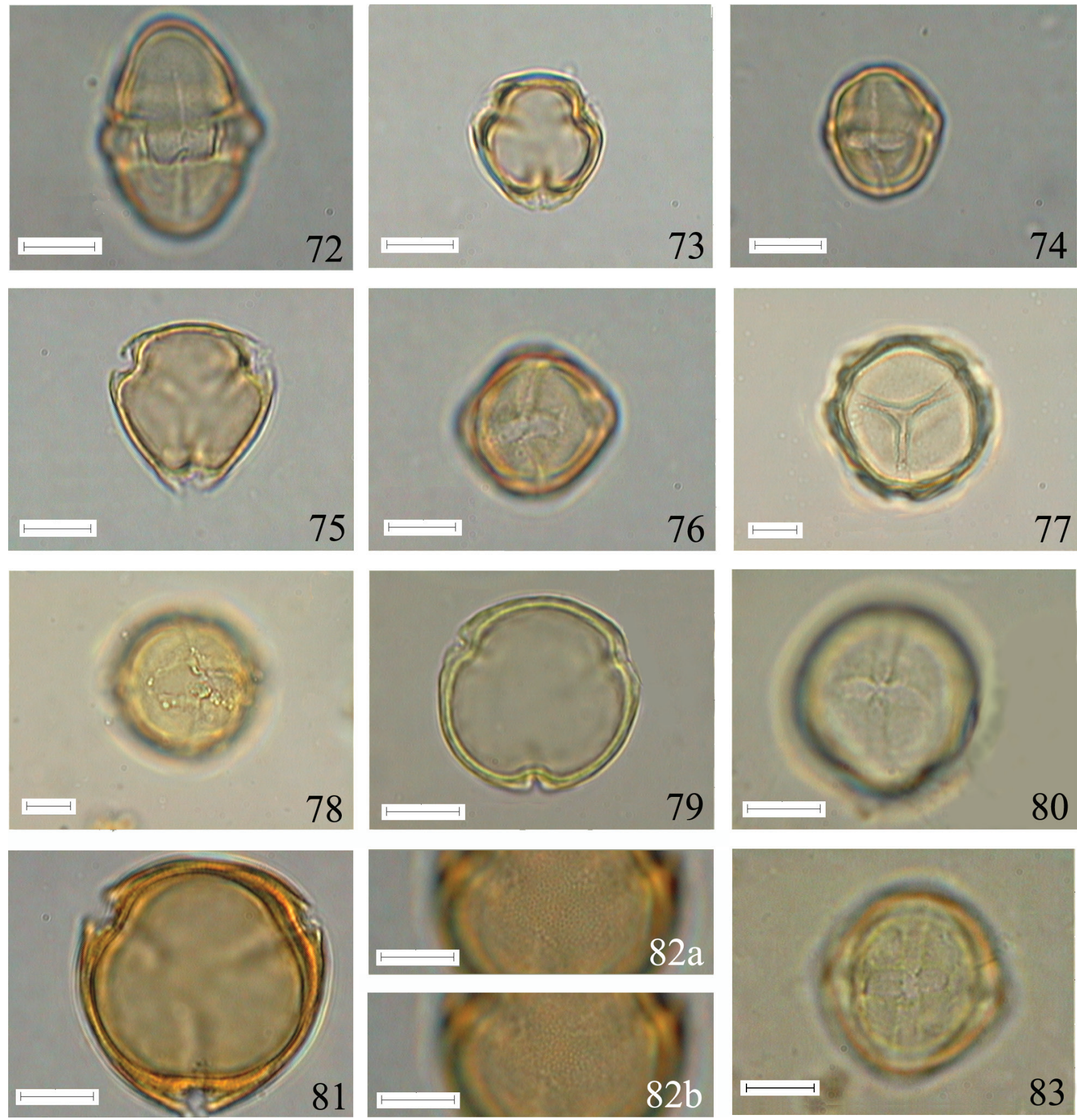

Figuras 72-83. Fotomicrografias dos grãos de pólen do gênero Solanum (Solanaceae). Figura 72. Solanum hoehnei Morton. Vista equatorial evidenciando as endoaberturas. Figuras 73-74. Solanum inaequale Vell. 73. Vista polar. 74. Vista equatorial evidenciando o cólporo. Figuras 75-76. Solanum inodornum Vell. 75. Vista polar. 76. Vista equatorial evidenciando o cólporo. Figuras 77-78. Solanum lycocarpum St. Hil. ex Dun. 77. Vista polar. 78. Vista equatorial evidenciando o cólporo. Figuras 79-80. Solanum mauritianum Scop. 79. Vista polar. 80. Vista equatorial evidenciando o cólporo. Figuras 81-82. Solanum paniculatum L. 81. Vista polar. 82. L.O. em dois níveis de focalização. Figura 83. Solanum rufescens Sendtn. Vista equatorial evidenciando o cólporo. Barras da escala = $5 \mu \mathrm{m}(82) ; 10 \mu \mathrm{m}(72-81,83)$.

Figures 72-83. Photomicrographs of pollen grains of genus Solanum (Solanaceae). Figure 72. Solanum hoehnei Morton. Equatorial view showing the endoapertures. Figures 73-74. Solanum inaequale Vell. 73. Polar view. 74. Equatorial view showing aperture. Figures 75-76. Solanum inodornum Vell. 75. Polar view. 76. Equatorial view showing aperture. Figures 77-78. Solanum lycocarpum St. Hil. ex Dun. 77. Polar view. 78. Equatorial view showing aperture. Figures 79-80. Solanum mauritianum Scop. 79. Polar view. 80. Equatorial view showing aperture. Figures 81-82. Solanum paniculatum L. 81. Polar view. 82. L.O. in high and low focus. Figure 83. Solanum rufescens Sendtn. Equatorial view showing aperture. Bar $=5 \mu \mathrm{m}(82) ; 10 \mu \mathrm{m}(72-81,83)$. 
(SP), T. Sendulsky 463 (SP), J.S. Silva 300 (SP), M.S.F Silvestre 21 (SP), M.S.F. Silvestre 214 (SP) e M.S.F. Silvestre 245 (SP), citados por Carvalho (1985) não foram estudados por possuírem apenas frutos ou por apresentarem grãos de pólen amassados. Para os espécimes de herbário aqui estudados constatou-se a presença de grãos de pólen com 3 e 4 aberturas nas seguintes frequências: SP155282, 3 aberturas $=92 \%$, 4 aberturas $=8 \%$; SP113843, 3 aberturas $=95 \%, 4$ aberturas $=5 \%$ e SP161003, 3 aberturas $=99 \%, 4$ aberturas $=1 \%$.

Material estudado: 10-VIII-1979, A. Custodio Filho 125 (SP); 9-XI-1978, H. Makino et al. 147 (SP); 13-X-1970, T. Sendulsky 1037 (SP).

\section{Solanum sisymbriifolium Lam.}

Figura 85

Forma: oblato-esferoidal a prolato-esferoidal, âmbito subtriangular.

Aberturas: 3 cólporos, colpos longos, com margem; endoaberturas lalongadas, extremidades arredondadas, com margem, presença de fastígio não conspícuo.

Exina: microrreticulada.

Medidas ( $\mu \mathrm{m}):$ T. Sendulsky 498: $\mathrm{P}=28,3 \pm 0,3$; $\mathrm{E}=31,3 \pm 0,3$; diâm. equatorial em vista polar $=31,3 \pm 0,4$; apocolpo ca. 6,1 ; cólporo larg. ca. 4,1, margem ca. 0,9 ; endoabertura compr. ca. 6,8 , larg. ca. 16,8, margem ca. 1,2 ; exina ca. 1,8 , sexina ca. 1,2 , teto ca. 0,5 e nexina ca. 0,8 .

J.A. Corrêa 23: $\mathrm{P}=30,6 ; \mathrm{E}=29,2$; diâm. equatorial em vista polar $=31,1$.

O. Handro 55: $\mathrm{P}=33,9 ; \mathrm{E}=33,4$; diâm. equatorial em vista polar $=33,4$;

Observações: Os materiais da Reserva G. Davidse \& W.G. D'Arcy 10473 (SP), C.G. Fonseca 36 (SP), F.C. Hoehne s.n. (SP31793), T. Sendulsky 547 (SP) e B. Skvortzov s.n. (SP105668), citados por Carvalho (1985), apresentaram grãos de pólen amassados. Alguns dados aqui obtidos para os grãos de pólen de S. sisymbriifolium diferem dos observados por Batista-Franklim \& Gonçalves-Esteves (2008). As autoras descreveram a extremidade da endoabertura como aguda e a ornamentação da sexina como granulada e, no presente estudo, como citado, foram observadas extremidades das endoaberturas arredondadas e ornamentação microrreticulada.

Material estudado: 28-X-1964, J.A. Corrêa 23
(SP); 13-I-1949, O. Handro 55 (SP); 7-XII-1966, T. Sendulsky 498 (SP).

19. Solanum swartzianum Roem. \& Schult. Figuras 86-87

Forma: prolato-esferoidal, âmbito subtriangular.

Aberturas: 3 cólporos, colpos longos, com margem; endoaberturas lalongadas, constritas, com extremidades afiladas, recobertas por membrana esculturada, com margem; presença de fastígio não conspícuo.

Exina: escabrada.

Medidas $(\mu \mathrm{m}):$ F. Barros 538: $\mathrm{P}=24,3 \pm 0,2$; $\mathrm{E}=22,2 \pm 0,2$; diâm. equatorial em vista polar $=22,7 \pm 0,2$; apocolpo ca. 2,8; colpo larg. ca. 3,2, margem ca. 1,1; endoabertura compr. ca. 3,9, larg. ca. 9,9, margem ca. 1,0; exina ca. 1,9, sexina ca. 1,3 , teto ca. 0,6 e nexina ca. 0,7 .

M. Kirizawa 425: $\mathrm{P}=22,9 ; \mathrm{E}=23,0$; diâm. equatorial em vista polar $=22,5$.

Observações: Os materiais da Reserva A. Custodio Filho et al. 22 (SP), G. Davidse \& W.G. D'Arcy 10448 (SP), S.L. Jung et al. 198 (SP), S.L. Jung et al. 323-C (SP), H. Makino 11 (SP), H. Makino 64 (SP), T. Sendulsky 1001 (SP), J.S. Silva 4 (SP), M.S.F. Silvestre 12 (SP), M.S.F. Silvestre 17 (SP) e M.S.F. Silvestre 22 (SP), citados por Carvalho (1985), apresentaram grãos de pólen amassados. Não foi possível medir o comprimento do cólporo por este ser muito longo.

Material estudado: 10-XI-1980, F. Barros 538 (SP);

7-VIII-1979, M. Kirizawa 425 (SP).

\section{Solanum vaillantii Dun.}

Figuras 88-90

Forma: prolato-esferoidal, âmbito subtriangular.

Aberturas: 3 cólporos, colpos longos, com margem; endoaberturas lalongadas, com margem, formando um anel contínuo ao redor do grão de pólen (endocingulo), presença de fastígio não conspícuo.

Exina: escabrada

Medidas $(\mu \mathrm{m}): \mathrm{P}=31,7 \pm 0,4 ; \mathrm{E}=27,7 \pm 0,2 ;$ diâm. equatorial em vista polar $=28,0 \pm 0,2$; apocolpo ca. 7,6; cólporo larg. ca. 4,3, margem ca. 1,4; endoabertura compr. ca. 6,4 , margem. ca. 1,5 ; exina ca. 1,5 , sexina ca. 0,9 , teto ca. 0,6 e nexina ca. 0,6 .

Material estudado: 25-X-1935, O. Handro s.n. (SP49476). 

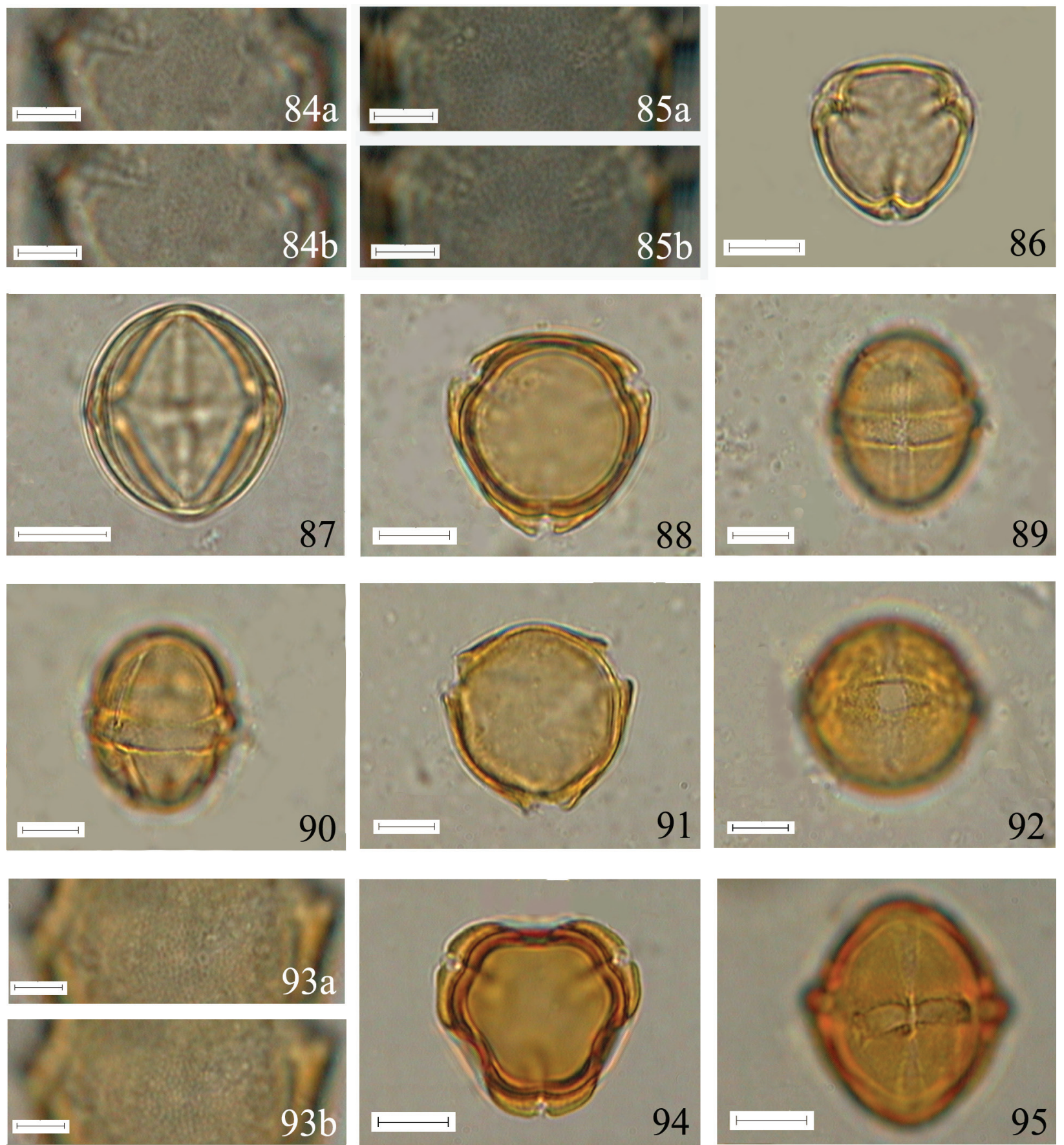

Figuras 84-95. Fotomicrografias dos grãos de pólen do gênero Solanum (Solanaceae). Figura 84. Solanum rufescens Sendtn. L.O. em dois níveis de focalização. Figura 85. Solanum sisymbriifolium Lam. L.O. em dois níveis de focalização. Figuras 86-87. Solanum swartzianum Roem. et Schult. 86. Vista polar. 87. Vista equatorial evidenciando as aberturas laterais. Figuras 88-90. Solanum vaillantii Dun. 88. Vista polar. 89. Vista equatorial evidenciando o cólporo. 90. Vista equatorial evidenciando as endoaberturas. Figuras 91-93. Solanum variabile Mart. 91. Vista polar. 92. Vista equatorial evidenciando o cólporo. 93. L.O. em dois níveis de focalização. Figuras 94-95. Solanum viarum Dun. 94. Vista polar. 95. Vista equatorial evidenciando o cólporo. Barras da escala $=5 \mu \mathrm{m}(84,85,93) ; 10 \mu \mathrm{m}(86-92,94-95)$.

Figures 84-95. Photomicrographs of pollen grains of genus Solanum (Solanaceae). Figure 84. Solanum rufescens Sendtn. L.O. in high and low focus. Figure 85. Solanum sisymbriifolium Lam. L.O. in high and low focus. Figures 86-87. Solanum swartzianum Roem. et Schult. 86. Polar view. 87. Equatorial view showing lateral apertures. Figures 88-90. Solanum vaillantii Dun. 88. Polar view. 89. Equatorial view showing aperture. 90. Equatorial view showing the endoapertures. Figures 91-93. Solanum variabile Mart. 91. Polar view. 92. Equatorial view showing aperture. 93. L.O. in high and low focus. Figures 94-95. Solanum viarum Dun. 94. Polar view. 95. Equatorial view showing aperture. $\operatorname{Bar}=5 \mu \mathrm{m}(84,85,93) ; 10 \mu \mathrm{m}(86-92,94-95)$. 


\section{Solanum variabile Mart.}

Figuras 91-93

Forma: oblato-esferoidal a prolato-esferoidal, âmbito subtriangular.

Aberturas: 3 cólporos, colpos longos, com margem; endoaberturas lalongadas, extremidades arredondadas, com margem, providas de fastígio.

Exina: microrreticulada

Medidas $(\mu \mathrm{m}):$ F. Barros 532: $\mathrm{P}=30,1 \pm 0,3$; $\mathrm{E}=32,5 \pm 0,3$; diâm. equatorial em vista polar $=33,1 \pm 0,3$; apocolpo ca. 9,2; cólporo larg. ca. 4,4 margem ca. 1,0; endoabertura compr. ca. 8,4, larg. ca. 19,8, margem ca. 1,2; exina ca. 2,0, sexina ca. 1,3 , teto ca. 0,5 e nexina ca. 0,7 .

G. Davidse \& W.G. D'Arcy 1045: $\mathrm{P}=33,1$; $\mathrm{E}=32,9$; diâm. equatorial em vista polar $=33,1$;

W. Mantovani 21: $\mathrm{P}=32,8 ; \mathrm{E}=31,3$; diâm. equatorial em vista polar $=31,5$;

T. Sendulsky 974: $\mathrm{P}=37,6 ; \mathrm{E}=34,9$; diâm. equatorial em vista polar $=33,6$.

Observações: Os materiais da Reserva R. Faria et. al. s.n. (SP99423), O. Handro s.n. (SP51583) e M. Kuhlmann s.n. (SP154572), citados por Carvalho (1985), apresentaram grãos de pólen amassados. Não foi possível medir o comprimento do colpo por esse ser muito longo.

Material estudado: 14-X-1980, F. Barros 532 (SP);
21-II-1976, G. Davidse \& W.G. D'Arcy 1045 (SP); 10-IV-1979, W. Mantovani 21 (SP); 10-VII-1968, T. Sendulsky 974 (SP).

\section{Solanum viarum Dun.}

Figuras 94-95

Forma: prolato-esferoidal, âmbito subtriangular.

Aberturas: 3 cólporos, colpos longos, com margem; endoabertura lalongada, com leve constrição mediana, extremidades truncadas, com margem; presença de fastígio conspícuo.

Exina: escabrada.

Medidas $(\mu \mathrm{m}): \mathrm{P}=31,2 \pm 0,2 ; \mathrm{E}=29,6 \pm 0,2 ;$ diâm. equatorial em vista polar $=28,1 \pm 0,2$; apocolpo ca. 8,3; cólporo larg. ca. 3,5, margem ca. 1,1; endoabertura compr. ca. 5,6, larg. ca. 15,9, margem ca. 1,4 ; exina ca. 1,7 , sexina ca. 1,2 , teto ca. 0,5 e nexina ca. 0,6 .

Observações: Os materiais da Reserva T. Sendulsky 648 (SP) e T. Sendulsky 623B (SP), citados por Carvalho (1985), não foram estudados por possuírem apenas frutos, tendo sido estudado o material SP44406, proveniente de outra localidade.

Material estudado: BRASIL. São Paulo: Campinas, Instituto Agronômico, 10-II-1938, A.S. Costa 1558 (SP).

\section{Chave para as espécies de Solanum}

1. Grãos de pólen psilados, escabrados

2. Grãos de pólen psilados

S. bulbatum

2. Grãos de pólen escabrados

3. Endoaberturas com endocíngulo

3. Endoaberturas sem endocíngulo

4. Endoaberturas com extremidades arredondadas ou afiladas

5. Colpos longos, com margem; endoaberturas com extremidades afiladas

S. swartzianum

5. Colpos curtos, sem margem; endoaberturas com extremidades arredondadas S. inaequale

4. Endoaberturas com extremidades truncadas

6. Grãos de pólen providos de fastígio conspícuo, endoaberturas com constrição mediana S. americanum

S. viarum

6. Grãos de pólen sem fastígio conspícuo, endoaberturas sem constrição mediana S. cernuum

1. Grãos de pólen microrretículado, rugulado

7. Grãos de pólen rugulados

8. Endoaberturas com extremidades truncadas, sem constrição mediana S. excelsum

8. Endoaberturas com extremidades arredondadas, com constrição mediana

9. Comprimento da endoabertura $<6,00 \mu \mathrm{m}$; diâmetro polar em vista equatorial $<28,00 \mu \mathrm{m}$ 
9. Comprimento da endoabertura $>7,00 \mu \mathrm{m}$; diâmetro polar em vista equatorial $>30,00 \mu \mathrm{m}$ S. lycocarpum

7. Grãos de pólen microrreticulados

10. Endoaberturas com extremidades truncadas

11. Endoaberturas com constrição mediana S. diflorum

11. Endoaberturas sem constrição mediana S.inodorum

10. Endoaberturas com extremidades afiladas ou arredondadas

12. Endoaberturas com extremidades arredondadas

13. Endoaberturas com constrição mediana S. concinnum

13. Endoaberturas sem constrição mediana S. granuloso-leprosum S. sisymbriifolium S. variabile

12. Endoaberturas com extremidades afiladas

14. Colpo com constrição mediana

15. Endoaberturas com constrição mediana, presença de fastígio não conspícuo S. mauritianum

15. Endoaberturas sem constrição mediana, presença de fastígio conspícuo S. didymum

14. Colpo sem constrição mediana

16. Endoaberturas com constrição mediana S. rufescens

16. Endoabertuas sem constrição mediana S. atropurpureum S. paniculatum

\section{Agradecimentos}

Os autores agradecem ao Programa Institucional de Bolsas de Iniciação Científica - PIBIC - CNPq, pelo auxílio financeiro concedido a Anedi Costa de Oliveira e Ligia Novac Souza.

\section{Literatura citada}

Al-Quran, S. 2004. Pollen morphology of Solanaceae in Jordan. Pakistan Journal of Biological Sciences 7: 1586-1593.

Anderson, G.J. \& Gensel, P.G. 1976. Pollen morphology and the systematics of Solanum section Basarthrum. Pollen et Spores 18: 533-552.

Barth, O.M. \& Melhem, T.S. 1988. Glossário ilustrado de palinologia. Universidade Estadual de Campinas, Campinas.

Barth, O.M. \& Duarte, S.G. 2008. Morfologia polínica de espécies arbóreas de Solanaceae do Estado de Santa Catarina, Brasil. Hoehnea 35: 379-386.

Batista-Franklim, C.P.R. \& Gonçalves-Esteves, V. 2002. Morfologia polínica de espécies de Brunfelsia L. (Solanaceae) ocorrentes no Estado do Rio de Janeiro. Revista Brasileira de Botânica 25: 137-145.

Batista-Franklim, C.P.R. \& Gonçalves-Esteves, V. 2008. Palinologia de espécies de Solanum L. (Solanaceae A. Juss.) ocorrentes nas restingas do Estado do Rio de Janeiro, Brasil. Acta Botanica Brasilica 22: 782-793.
Carvalho, L.D.F. 1985. Flora fanerogâmica da Reserva do Parque Estadual das Fontes do Ipiranga. (São Paulo, Brasil). 136-Solanaceae. Hoehnea 12: 67-85.

Cruz-Barros, M.A.V. \& Souza, L.N. 2005. Flora polínica da Reserva do Parque Estadual das Fontes do Ipiranga (São Paulo, Brasil). 10-Piperaceae. Hoehnea 32: 77-85.

Erdtman, G. 1952. Pollen morphology and plant taxonomyAngiosperms. Almquivist \& Wiksell, Stockholm.

Erdtman, G. 1960. The acetolysis method. A revised description. Svensk Botanisk Tidskrift 54: 61-564.

Huang, T.C. 1972. Pollen Flora of Taiwan. National Taiwan University, Botany Departament Press, Taiwan.

Melhem, T.S., Makino, H., Silvestre, M.S.F., Cruz, M.A.V. \& Jung-Mendaçolli, S.L. 1984. Planejamento para a elaboração da "Flora Polínica da Reserva do Parque Estadual das Fontes do Ipiranga (São Paulo, Brasil). Hoehnea 11: 1-7.

Melhem, T.S., Giulietti, A.M., Forero, E., Barroso, G.M., Silvestre, M.S.F., Jung, S.L., Makino, H., Melo, M.M.R.F., Chiea, S.C., Wanderley, M.G.L., Kirizawa, M. \& Muniz, C. 1981. Planejamento para a elaboração da Flora Fanerogâmica da Reserva do Parque Estadual das Fontes do Ipiranga (São Paulo, Brasil). Hoehnea 9: 63-74.

Melhem, T.S., Cruz-Barros, M.A.V., Corrêa, A.M.S., Makino-Watanabe, H., Silvestre-Capelato, M.S.F., \& Esteves, V.L.G. 2003. Variabilidade polínica em plantas de Campos do Jordão (São Paulo, Brasil). Boletim do Instituto de Botânica 16: 1-104. 
Murry, L.E. \& Eshbaugh,W.H. 1971. A palynological study of the Solaninae (Solanaceae). Grana 11: 65-78.

Natarajan, A.T. 1957. Studies in the morphology of pollen grains - Tubiflorae. Phyton 8: 21-42.

Persson, V., Knapp, S. \& Blackmore, S. 1994. Pollen morphology and systematic of tribe Juanulloeae A.T. Hunziker (Solanaceae). Review of Palaeobotany and Palynology 83: 1-30.

Perveen, A. \& Qaiser, M. 2007. Pollen morphology of family Solanaceae from Pakistan. Pakistan Journal of Botany 39: 2243-2256.

Punt, W. \& Monna-Brands, M. 1977. Solanaceae. Review of Palaeobotany and Palynology 23: 1-30.

Punt, W., Hoen, P.P., Blackmore, S., Nilsson, S. \& Le Thomas, A. 2007. Glossary of pollen and spore terminology. Review of Paleobotany and Palynology 143: 1-81.

Rao, A. \& Leong, F. 1974. Pollen morphology of certain tropical plants. Reinwartia 9: 1- 153.

Raynal, J. \& Raynal, A. 1971 Une techinique de preparation des grains de pollen fragiles. Andansonia 11: 77-79.

Roubik, D. W. \& Moreno P., J.E. 1991. Pollen and spores of Barro Colorado Island. Monographs in Systematic Botany 36: 1-268.
Salgado-Labouriau, M.L. 1973. Contribuição à palinologia dos Cerrados. Academia Brasileira de Ciências, Rio de Janeiro.

Salgado-Labouriau, M.L., Carvalho, L.D.F \& Cavalcante, P.B. 1969. Pollen grains of the "Cerrado" XXI Ebenaceae, Nyctaginaceae, Rhamnaceae and Solanaceae. Boletim do Museu Paraense Emílio Goeldi 32: 1-12.

Silva, S.N., Carvalho, A.M.V \& Santos, F.A.R. 2003. Morfologia polínica de doze espécies de Cestrum L. (Solanaceae) da mata higrófila na Bahia, Brasil. Acta Scientiarum Biological Sciences 25: 439-443.

Stafford, P. \& Knapp, S. 2006. Pollen morphology and systematics of the zygomorphic-flowered nightshades (Solanaceae; Salpiglossideae sensu D'Arcy, 1978 and Cestroideae sensu D'Arcy, 1991, pro parte): a review. Systematics and Biodiversity 4: 173-201.

Trigo. M.M. 1992. Contribution to the study of pollen in ornamental species Solanaceae, Convolvulaceae and Hydrophyllaceae. Acta Botanica Malacitana 17: 209-222.

Wiebke, M.L.\& Wiebke, G. 1974. Estudos de grãos de pólen de Solanaceae I. Estudos Leopoldinenses 29: 71-89. 